\title{
LA MEDIDA DE AMÉRICA: \\ DE LA OBSERVACIÓN MÉTRICA ILUSTRADA ESPAÑOLA AL EMPIRISMO RAZONADO HUMBOLDTIANO*
}

\author{
Miguel Ángel Puig-Samper \\ Consejo Superior de Investigaciones Cientificas
}

Ela ciencia pasó a ocupar un lugar central por su capacidad para transformar el mundo. Fue también el siglo de los grandes viajes y de las expediciones científicas. Esta conexión es la que obliga a trabajar las expediciones, la ciencia y los científicos como partes de un proyecto y de un mundo que dirigía su mirada a la conquista del saber. La obtención de mayores conocimientos sobre los recursos naturales, las poblaciones y los territorios fue una necesidad inherente a la gestión de los estados y, sobre todo, para lograr controlar y explotar de manera más racional los territorios coloniales de ultramar. El desarrollo de la ciencia necesitó y se sirvió de la expansión territorial y colonial, y

Fecha de recepción: $1^{\circ}$ de diciembre de 2016

Fecha de aceptación: 8 de marzo de 2017

*Proyecto de investigación HAR2016-75331-P del Ministerio de Economía, Industria y Competitividad (AEI.Feder.UE) 
fue esta presencia colonial la que contribuyó en gran medida al avance científico. Las expediciones colaboraron en el progreso de la ciencia a la vez que dotaron a los gobiernos europeos de información de los recursos naturales de sus colonias, lo que fue de suma importancia para controlar e iniciar una explotación más racional y provechosa de éstas. Por medio de las expediciones, de sus resultados y aplicaciones en los territorios coloniales y en las metrópolis podemos entender mejor la conexión y dependencia de la ciencia europea, metropolitana, y la colonial.

Además, en su vertiente colonial la ciencia ilustrada se obsesionó con tomar las medidas del territorio y con objetivar sus observaciones científicas, tanto en las mediciones hidrográficas como en las cartográficas, físicas, astronómicas, entre muchas otras, usando un arsenal cada vez mayor de instrumentos científicos, ${ }^{1}$ lo que en el caso español se tradujo en el envío de innumerables expediciones marítimas y terrestres encargadas de esta difícil misión, en la que ya estaban embarcadas otras potencias como Inglaterra y Francia. De hecho algunas de las primeras experiencias en este sentido se hicieron de la mano de los científicos franceses, casi siempre por encargo de la Académie des Sciences de París, una institución de prestigio con experiencia en el uso de instrumentos científicos que aparentemente objetivaban las observaciones, además de conferirles cierta autoridad ante diferentes audiencias y de crear puentes entre la ciencia natural y la cultura popular. ${ }^{2}$ Asimismo, como ha señalado

${ }^{1}$ Para entender de qué hablamos al usar la idea de "instrumentos científicos" es muy interesante la revisión de WARNER, "What is a scientific instrument".

2 Helden y Hankins, "Intruments”. Respecto a la objetivación de los 
Nuria Valverde, los ilustrados pondrán en entredicho la autoridad del conocimiento erudito y libresco, alejado del mundo, tendiendo hacia una nueva metáfora del conocimiento como viaje, que además abrió el camino a una concepción del error como imprecisión, algo que debía ser evitado. Una de las formas de hacerlo era el uso adecuado de los nuevos instrumentos científicos, que debían ser fiables desde su construcción meticulosa y siempre guiados por unas buenas instrucciones, una conservación exquisita, que permitía la calibración y una utilización experimentada por científicos entrenados, ya que el sujeto podía ser fuente de error. Algo en lo que insistiría Jorge Juan en una memoria sobre La fábrica y uso del quarto de círculo, al decir que el principal fundamento para prevenir la exactitud era valerse de buenos instrumentos, bien construidos y manejados por sujetos experimentados. Esto, sin duda, permitiría la comparación/replicación de resultados a estos nuevos científicos integrados a instituciones académicas y en redes internacionales de conocimiento, muchas veces impulsoras de las numerosas expediciones científicas ilustradas. ${ }^{3}$

\author{
LA EXPEDICIÓN GEODÉSICA \\ Y LA COLABORACIÓN HISPANOFRANCESA
}

Aunque desde principios del siglo XviII la marina española comienza un periodo de reformas importante, que incluye

resultados y las observaciones puede consultarse el interesante artículo de Daston y Galison, "The image of objectivity”, así como una reciente revisión del tema en Padovani, Ricardson y Tsou, Objectivity in Science. ${ }^{3}$ Valverde, Actos de precisión; véanse también Pimentel, Testigos del mundo y BATES, "The epistemology of error". 
la formación del nuevo marino científico y la renovación de los medios materiales e instrumentales, ${ }^{4}$ un salto cualitativo lo constituye la expedición geodésica a Quito (1735-1744), enmarcada en la polémica entre el newtonismo y el cartesianismo sobre la figura de la Tierra, y organizada ya como una auténtica expedición científica, con dotación de un equipo, medios instrumentales, instrucciones científicas, etc. ${ }^{5}$ Como nos recordó Lafuente hace años, Maupertuis comentó por entonces que esos años habían sido muy brillantes para las ciencias, en tanto que Voltaire lograba una difusión del problema de la figura de la Tierra (la sandía de Newton frente al melón cartesiano) inimaginable unos años antes, todo ello sumido en una disputa sobre las ciencias nacionales francesa y británica. ${ }^{6}$

El ministro francés de Marina, Conde de Maurepas, logró la aprobación real para este proyecto del astrónomo Louis Godin, quien dirigiría la expedición formada por un equipo que contaba con Charles de La Condamine, académico y geógrafo; Pierre Bouguer, matemático y astrónomo; Joseph Jussieu, médico encargado de la historia natural; Jean Seniergues, cirujano, Morainville, dibujante de historia natural; Verguin, ingeniero de minas, además de otros ayudantes y de los dos guardiamarinas españoles agregados, Jorge Juan y Antonio de Ulloa. Estos fueron admitidos una

${ }^{4}$ Para ver la evolución de los instrumentos usados por la marina véase Sellés, Instrumentos de navegación, y para la evolución de la cartografía marítima americana, Martín Merás, Cartografía maritima.

${ }^{5}$ Lafuente y Delgado, La geometrización de la Tierra. Lafuente y Mazuecos, Los caballeros del punto fijo.

${ }^{6}$ Lafuente, "Retórica y experimentación". SAfier, La medición del Nuevo Mundo. 
vez que las autoridades españolas dieron el visto bueno a la petición francesa que solicitaba autorización para recorrer parte del territorio del virreinato del Perú y tras el dictamen del Consejo de Indias. Fue este Consejo el que incluyó esa condición de añadir “dos sujetos inteligentes en la matemática y astronomía”, quizá recordando un mal precedente en esta colaboración científica hispanofrancesa, ya que en 1724, durante el breve reinado de Luis I, el ministro Juan Bautista Orendain había autorizado la estancia en las islas Canarias de Louis Feuillée, quien viajaba enviado por la Academia francesa para fijar el meridiano de Hierro y hacer observaciones naturalistas, y había sido rechazada por la parte francesa la presencia en la expedición de Nicolás Guerrero, de la Academia de Guardiamarinas de Cádiz. ${ }^{7}$

Ahora la colaboración científica tendría unos frutos brillantes, y más tarde también en la colaboración española en la expedición a la Baja California comandada por Chappe d'Auteroche para observar el paso de Venus por el disco del Sol en 1768, con el concurso de los guardiamarinas Salvador de Medina, que sustituyó al nombrado Juan de Lángara y murió en esta empresa californiana, al igual que el propio comandante Chappe, y Vicente Doz. ${ }^{8}$ Según un oficio de Julián de Arriaga al Marqués del Real Tesoro en diciembre de 1768, se autorizaba también el traslado del equipo

\footnotetext{
7 Puig-Samper y Pelayo, El viaje del astrónomo.

8 "Instrucción que han de observar los tenientes de navío don Juan de Lángara y don Vicente Doz en su viaje a California para observar el paso de Venus por el disco del Sol que ha de suceder el 3 de junio del próximo año de 1769". MN, ms. 147, ff. 39-40. La observación aparece en el mismo ms. ff. 32-37 y muestran las dudas por la precisión de los instrumentos y los posibles errores.
} 
francés que acompañaba a Chappe a América, compuesto por Juan Pedro Michel Pauly, geógrafo y astrónomo; Juan Santiago Dubois, relojero; Juan Noel Turelure, pintor, y Pedro Barnon, criado del señor Chappe. ${ }^{9}$

Como comentó hace tiempo Salvador Bernabéu, Chappe llegó a California literalmente sentado en su péndulo, un símbolo del nuevo hombre de ciencia ilustrado dependiente de las observaciones objetivas realizadas con los nuevos instrumentos. Los tenientes españoles llevaban al menos un “anteojo acromático" que el Conde de Fuentes había comprado en París. En este sentido hay que recordar la misma dependencia instrumental en los viajes de Cook, quien por cierto haría una experiencia similar en este mismo año tras la negativa española al Conde de Morton para una colaboración angloespañola para medir el paso de Venus por el disco del Sol en California. El propio Conde de Morton ya había sugerido la necesidad de usar buenos instrumentos en esta observación, en especial el cuarto de círculo, el reloj de péndulo y un telescopio con un micrómetro acromático. ${ }^{10} \mathrm{Con}$ instrumentos semejantes Vicente Doz situaría poco después la latitud y longitud de Veracruz y La Habana, en este intento de la marina española de medir y situar los lugares y las ciudades de su inmenso imperio. ${ }^{11}$

Aunque en principio los propósitos de esta expedición hispanofrancesa dirigida por Godin estaban encaminados fundamentalmente a fines geodésicos y astronómicos, las autoridades españolas no dejaron de señalar a Jorge Juan y

\footnotetext{
9 AGI, Contratación, 5511B, N. 2, R. 69.

10 Bernabéu, Las huellas de Venus.

11 Bernabéu, "La Comisión española".
} 
Antonio de Ulloa que tuvieran el cuidado de examinar las plantas, sus virtudes, y sobre todo de dibujarlas, conocedores de la presencia especializada de Joseph de Jussieu en esta empresa científica. Evidentemente los académicos franceses contaban con un instrumental adecuado para las mediciones del meridiano y las observaciones astronómicas que debían realizar (cuartos de círculo, un sector astronómico de 12 pies de radio - luego sustituido por otro de 18 pies de radio construido en Quito-, el péndulo horario, varios anteojos y el patrón de medida), en tanto que los españoles no contaron con instrumentos sino hasta Quito, ya que no llegaron antes los encargados a París, aunque como ya señalaban las instrucciones en su punto octavo, estaban autorizados a utilizar los de los académicos franceses en tanto no llegaran los suyos. Jorge Juan manifestó poco después cómo, además de las tareas propias de medición del meridiano, habían ejecutado otras mediciones muy útiles, como las determinaciones de longitud y latitud para la precisión en las cartas, el levantamiento de planos de bahías, costas, ciudades y ríos, la observación de los vientos, las variaciones de la aguja para el gobierno de los pilotos, experiencias con el barómetro, velocidad del sonido, dilatación de los metales, experiencias de gravedad con el péndulo, aunque siempre con dudas respecto a la precisión instrumental y el error en las mediciones. ${ }^{12}$

La organización y el envío de expediciones españolas a los dominios coloniales fue resultado de una serie de factores políticos, como la delimitación de fronteras y el control de la expansión de otras potencias imperiales; económicos, como el aumento del comercio, la contención del

12 Ramos, Las noticias secretas, pp. 23-31. 
contrabando y la explotación de nuevos recursos naturales; demográficos y cartográficos. La convicción de que los mares estaban llamados a convertirse en los "teatros" del enfrentamiento entre las potencias europeas obligó a proteger algunas áreas del ultramar español: el Caribe, el noroeste del continente americano y el Cono Sur, con una atención preferencial a los estrechos que daban paso a estas zonas estratégicas del Imperio español.

\section{LAS EXPEDICIONES DE LÍMITES}

Entre las primeras expediciones que queremos recordar se encuentran aquellas destinadas a fijar de fronteras entre los dominios españoles y portugueses en América, conocidas como expediciones de límites. ${ }^{13} \mathrm{~L}$ a tensión provocada por el enfrentamiento entre españoles y portugueses estaba a punto de provocar un serio conflicto en el área sudamericana. La política exterior de Fernando VI intentó resolver el problema con la firma, en 1750, del Tratado de Madrid, por el que se reconocían las posesiones españolas y portuguesas en la América Meridional, de acuerdo con el rey portugués D. João V. La comisión encargada de fijar los límites en el sur estuvo dirigida por el comisario Marqués de Valdelirios, bajo la atenta mirada del ministro español José Carvajal y Lancaster, en tanto que por la parte portuguesa intervino el "mestre de campo" general Tomás da Silva Teles, Vizconde de Vila Nova de Cerveira, con la inestimable ayuda de Alexandre de Gusmão. ${ }^{14}$ La expedición, que partió de Cádiz

13 Puig-Samper, Las expediciones científicas.

14 Paranhos de Rio-Branco, Alexandre de Gusmão. 
el 16 de noviembre de 1751, estuvo compuesta por tres secciones o partidas con el fin de delimitar zonas diferentes en la línea de demarcación, siempre contando con la instrumentación necesaria. La primera, capitaneada por Juan de Echevarría, tenía por objeto fijar la frontera desde Castillos Grandes hasta la boca del Ibicuy, tarea que no resultó nada fácil, ya que, una vez reunidas las comisiones hispanoportuguesas en 1752 y acordada la entrega por parte española de las siete misiones jesuítico guaraníes, los expedicionarios se encontraron con la resistencia armada de los indios de las antiguas reducciones, por lo que tuvieron que detener sus actividades en Santa Tecla.

La segunda partida, comandada por Francisco Arguedas, tuvo como misión fijar los límites desde el último punto de la primera hasta el salto grande del Paraná. Aunque no logró pasar el salto de Iguazú, determinó que los territorios situados al oeste y sur de los ríos Pepirí, San Antonio e Iguazú eran de soberanía española, en tanto que los que se extendían al norte y al este pertenecían a los portugueses. Las tareas de esta segunda partida acabaron en San Nicolás en abril de 1760. La tercera partida fue dirigida por el capitán de fragata Manuel Antonio de Flores, quien recibió órdenes para fijar la frontera desde el territorio intermedio entre el Paraná y el Paraguay hasta el río Jaurú. Los trabajos de esta tercera partida fueron de extraordinaria importancia puesto que, aunque fracasaron en la determinación del río Corrientes, reconocieron el Paraguay, el Paraná, el Gatimí y el Ipané-Guazú, además de efectuar trabajos de espionaje en puntos estratégicos de influencia portuguesa. Para efectuar los estudios de la línea de demarcación en el norte, se envió la conocida expedición al Orinoco, al mando del capitán de 
navío José de Iturriaga. Además, se nombraron comisarios de la expedición a Eugenio Alvarado, al teniente de navío Antonio de Urrutia y al alférez de navío José Solano. ${ }^{15} \mathrm{La}$ expedición de Iturriaga llegó el 9 de abril de 1754 a Cumaná, punto de partida desde el que debían dirigirse hacia el sur en busca de los portugueses, con lo que debían reunirse en las inmediaciones del río Negro.

La actividad de los expedicionarios aumentó de forma considerable tras el nombramiento como cuarto comisario de Diguja, gobernador de Cumaná y Guayana. Entre 1758 y 1760 se producen las exploraciones más detalladas del territorio, se fundan pueblos - como San Fernando y San Carlos-, y tienen lugar los viajes de Díez de la Fuente hacia el nacimiento del Orinoco, y de Fernández de Bobadilla al río Negro. El contacto con los portugueses se produjo en 1759, cuando sus fuerzas expedicionarias ya estaban prácticamente desintegradas y su comisario Mendonça Furtado se retiraba enfermo. En junio de 1760, el secretario de Estado, Wall, ordenó la finalización de la expedición, por lo que la mayoría de los miembros de las distintas partidas inició el regreso a España en la primavera de 1761. Una vez muerto Fernando VI, en 1759, la validez de los acuerdos entre las dos potencias ibéricas quedó en suspenso, mientras continuaban los conflictos directos en la zona de Sacramento.

La siguiente expedición que envió la corona española con fines de exploración fue la de la Rosalía, con el marino Juan de Lángara, que efectuó diferentes trabajos geográficos en Trinidad del Sur, Río Grande y Santa Catalina, antes

${ }^{15}$ Lucena Giraldo, Laboratorio tropical; Lucena Giraldo y De Pedro, La frontera caríbica. 
de la firma del tratado preliminar de límites hispanoportugués de 1777. Según éste, la puesta en práctica de una línea de frontera volvía a recaer en manos de comisiones de límites, por lo que de nuevo se iniciaron las tareas cartográficas con una expedición a la América Meridional y otra al norte, conocida como comisión del Marañón. Como ha señalado $\mathrm{M}^{\mathrm{a}}$ Luisa Martín-Merás, la experiencia de las demarcaciones del tratado de 1750 sirvió para una organización más técnica, especialmente en lo referente a los instrumentos científicos. El físico e instrumentista portugués João Jacinto de Magalhães (1722-1790) fue encargado por Lisboa de comprar instrumentos científicos en Londres, algo que también se hizo desde Madrid. ${ }^{16}$ En abril de 1780 se mandaron desde Londres once colecciones de instrumentos; seis fueron destinadas a Madrid y cinco a Lisboa. ${ }^{17}$

16 ReIs, João Jacinto de Magalhães (1722-1790).

17 Cada colección se componía de 12 cajas de libros e instrumentos. Los instrumentos científicos que componían cada una de las ocho colecciones que llegaron a Europa eran los siguientes: 1 péndulo astronómico de Graham a segundos muertos; 2 anteojos acromáticos de Dollon de triple objetivo de $31 / 2$ pies de foco y el otro de 2 pies; 2 lunetas o anteojos acromáticos de triple objetivo con bastidor de 3 hilos horizontales y 1 vertical; 2 tubos de oculares para objetos celestes y terrestres, vidrios ahumados y verdes para observaciones del Sol; 1 iluminador de marfil para estrellas; 1 espejo de reflexión de acero con plomo oblicuo de $45^{\circ}$ para practicar fácilmente la medición del zenit; 2 anteojos de mano portátiles; 1 reloj de plata de faltriquera a segundos libres de Graham; 1 cuarto de círculo de 1 pie de radio fabricado por Simpson; 1 teodolito de 10 pulgadas de diámetro montado sobre un pedestal de madera de 3 pies, ideado por Magallanes; varias agujas de navegar; 2 teodolitos de faltriquera con bastones para fijarlos en tierra y marcar objetos; 1 sextante de ébano de 12 pulgadas de radio con anteojos acromáticos para observaciones de cara a los astros; 1 instrumento circular de latón de 10 pulgadas de diámetro con luneta acromática, propuesto por Mayer 
La expedición a la América Meridional (1781-1801) estuvo dirigida por el capitán de navío José Varela y Ulloa, con el concurso de los comisarios Diego de Alvear, Félix de Azara y Juan Francisco de Aguirre, que encabezaban diferentes partidas. Los grupos de Varela y Alvear debían realizar sus tareas entre el litoral y la cabecera del río Negro, hasta encontrarse, en febrero de 1784, con los portugueses en el arroyo del Chuy. Dos años dedicaron estas partidas a las tareas de demarcación en la zona de la laguna de Merín, hasta que se separaron con el fin de que la segunda partida se dirigiera a reconocer el área de Iguazú, mientras que la primera trabajaba en Cuchilla Grande y exploraba, más tarde, el Pepirí-Guazú, hasta que llegó la orden de disolución de las partidas demarcadoras en 1801.

Por otro lado, la comisión del Marañón (1778-1804), al mando de Francisco Requena, ${ }^{18}$ recorrió en un año, desde enero de 1780, el territorio comprendido entre Quito y Tabatinga, para reconocer después los ríos Javarí, Japurá y Apaporis. Las diferencias con los portugueses y la inutilidad de las exploraciones para definir una línea de frontera hicieron que Requena, que se había instalado en Tefé,

en 1770; 1 barómetro de Nairme y Blunt de 3 1/2 pies de largo con 2 escalas francesa e inglesa desde 13 hasta 22 pulgadas; 2 termómetros de Nairn y Blunt de faldriquera; 1 miriámetro filar para medir los diámetros del sol y los planetas colocándolo en el ocular del anteojo grande; otros varios nicómetros pequeños; 2 estuches completos de matemática con compás simple de proporción, transferidor, escalas; 1 transferidor de latón de 5 pulgadas de radio dividido en $360^{\circ}$; varias reglas de ingeniosa construcción; 1 cadena de 20 toesas con 120 eslabones de 1 pie de rey de París cada uno; barras magnéticas artificiales en su estuche de madera; 1 caja con colores y pinceles.

${ }^{18}$ Beerman, Francisco Requena. 
se retirase a Mainas en 1791, mientras que el resto de los expedicionarios tuvieron que seguir con los trabajos de demarcación, hasta que el gobierno metropolitano ordenó, en 1804, la disolución definitiva de la comisión del Marañón. El resultado fue una valiosa colección cartográfica, parte de la cual se encuentra en la Biblioteca del Congreso en Washington, y una serie de acuarelas que muestran la actividad científica de Requena y su expedición, conservadas en la Universidad Católica de la misma ciudad.

\section{LA EXPLORACIÓN DEL NOROESTE}

Otra área de actuación de estas expediciones españolas, que intentaban contener el avance de las otras potencias europeas reconociendo el territorio valiéndose de los nuevos conocimientos matemáticos y astronómicos de la nueva marina científica, fue la de las costas californianas y el noroeste de América, zonas de gran potencial estratégico desde un punto de vista político y económico, en las que los rusos, franceses, ingleses y estadounidenses intentarían establecer bases desde las que pudieran lanzar viajes de exploración. ${ }^{19}$ Las navegaciones de reconocimiento de la costa noroeste americana tuvieron como base en la establecida en el puerto de San Blas. La primera de estas expediciones fue la comandada por Juan Pérez, en 1774, a bordo de la fragata Santiago, que consiguió llegar hasta los $55^{\circ}$ de latitud y pudo reconocer las costas de San Lorenzo de Nutka, que luego Cook pretendió descubrir. Un año más tarde volvió

19 Fuster, El final del descubrimiento; BernabÉu, La aventura de lo imposible. 
a enviarse una nueva expedición, compuesta esta vez por la Santiago, la goleta Sonora y el paquebote San Carlos, capitaneada por Bruno de Ezeta, Juan Francisco de la Bodega y Quadra, y Miguel Manrique, que pudo alcanzar los $58^{\circ}$ de latitud norte en el golfo de Alaska. ${ }^{20} \mathrm{La}$ tercera de las expediciones enviadas a la costa norte, en 1779, fue la integrada por las fragatas Princesa y Nuestra Señora de los Remedios, alias la Favorita, al mando de Ignacio Arteaga y Juan Francisco de la Bodega y Quadra. ${ }^{21}$ Esta vez, después de avistar el cabo y las montañas de San Elías, lograron alcanzar los $60^{\circ}$ de latitud norte en el puerto de Santiago, antes de regresar a San Blas.

El periodo comprendido entre 1779 y los primeros años de la década de 1780 fue de relativa inactividad exploratoria, pero la información sobre los establecimientos rusos en las proximidades de Nutka volvió a decidir al gobierno español al envío de nuevas expediciones de exploración. Entre éstas, hay que destacar la enviada desde San Blas, en 1788, al mando de Esteban José Martínez, a bordo de la Princesa, secundado por Gonzalo López de Haro, capitán del paquebote San Carlos, alias el Filipino, con el objetivo de alcanzar los $61^{\circ}$ de latitud norte. La última expedición de interés, antes de la exploración de Malaspina, se llevó a cabo entre 1790 y 1791 por orden de Bodega y Quadra, que quería reforzar las defensas de Nutka y proclamar la soberanía española en la costa noroeste americana, ante posibles incursiones de otras potencias europeas.

20 Bernabéu, Trillar los mares.

${ }^{21}$ Bernabéu, Juan Francisco de la Bodega y Quadra. 
Por otra parte, la exploración de los ingleses y franceses de la costa patagónica y sus deseos de asentarse en ella y en las islas Malvinas motivaron el envío, en 1785, de la fragata Santa María de la Cabeza, al mando del capitán de navío Antonio de Córdova con Fernando de Miera como segundo comandante, con un total de 277 personas a bordo. La novedad en este viaje era aprovechar la experiencia de Vicente Tofiño y su equipo en la preparación del Atlas marítimo de España, tanto en personal como en métodos y herramientas. La expedición se preparó con los mejores aparatos e instrumentos científicos (llevaban a bordo los relojes de longitud no 15 y 16 de Berthoud del Observatorio de Cádiz y un Arnold pequeño n ${ }^{\circ}$ 71, propiedad de Alejandro Malaspina, quien también facilitó una pequeña colección de libros de viajes, además de una colección completa de instrumentos de las formadas en Londres por Jacinto Magallanes y los mejores quintantes y sextantes ingleses) y con una tripulación escogida, en la que se encontraban Dionisio Alcalá-Galiano, Cosme Damián Churruca y Ciriaco Cevallos, entre los marinos, y Luis Sánchez como naturalista. La estancia de los marinos en el estrecho de Magallanes dio como resultado la elaboración de los mejores mapas y cartas de esta región, en total 61, a pesar de que los expedicionarios no habían podido completar su viaje por las condiciones climatológicas adversas. Además, los marinos siempre tuvieron dudas razonables sobre los errores de medición de sus instrumentos, algo que persiguió siempre a los científicos ilustrados y que 
aparece presente en la Relación oficial del viaje. ${ }^{22}$ Esta circunstancia obligó al gobierno español a enviar una segunda expedición, realizada en 1788 y 1789, con Antonio de Córdova al mando de los paquebotes de menor calado Santa Casilda y Santa Eulalia, con el concurso de los oficiales Miera, Churruca y Cevallos, los cuales pudieron terminar de cartografiar el estrecho hasta su desembocadura en el Pacífico, ${ }^{23}$ con un gran arsenal de instrumentos científicos comprados en Inglaterra para el Atlas de Tofiño y que quedaron bajo la custodia de Cosme de Churruca. ${ }^{24}$

El resultado de estas mediciones del estrecho, según expresa el intendente general de la Marina Luis María de Salazar, fue el siguiente:

$1^{\circ}$ Una carta esférica de la parte Sur de la América meridional, en la cual se halla colocado el estrecho de Magallanes; y se comprehenden también el plano de la bahía de Buen-Suceso en la costa occidental del estrecho de Maire: otro de la bahía de la Soledad en la costa occidental de las islas Malvinas, y otro del puerto de Año-Nuevo en la costa Norte de la isla de los Estados. Esta carta es del año de 1788, y está grabada por Selma.

22 Relación del último viage al estrecho.

23 Oyarzun, Exploraciones españolas al Estrecho.

${ }^{24}$ Los instrumentos que llevaba esta expedición eran los siguientes: un cuarto de círculo de 2 pies ingleses de radio, un péndulo, dos anteojos acromáticos, un teodolito, una cadena de 100 pies ingleses y un barómetro marino. Por su parte el comandante Malaspina cedió el reloj de faltriquera $\mathrm{n}^{\circ} 71$ de Arnold que estaba dispuesto para su expedición por no haberse limpiado aún los relojes marinos del Observatorio de San Fernando. Además, llevaban para realizar los levantamientos de las cartas: un estuche con lapicero, compás y pantómetra, una caja de barras magnéticas; plancha para sostener la aguja, círculo de reflexión, segundero de faltriquera, cajita de pintura, transporte de planos. 


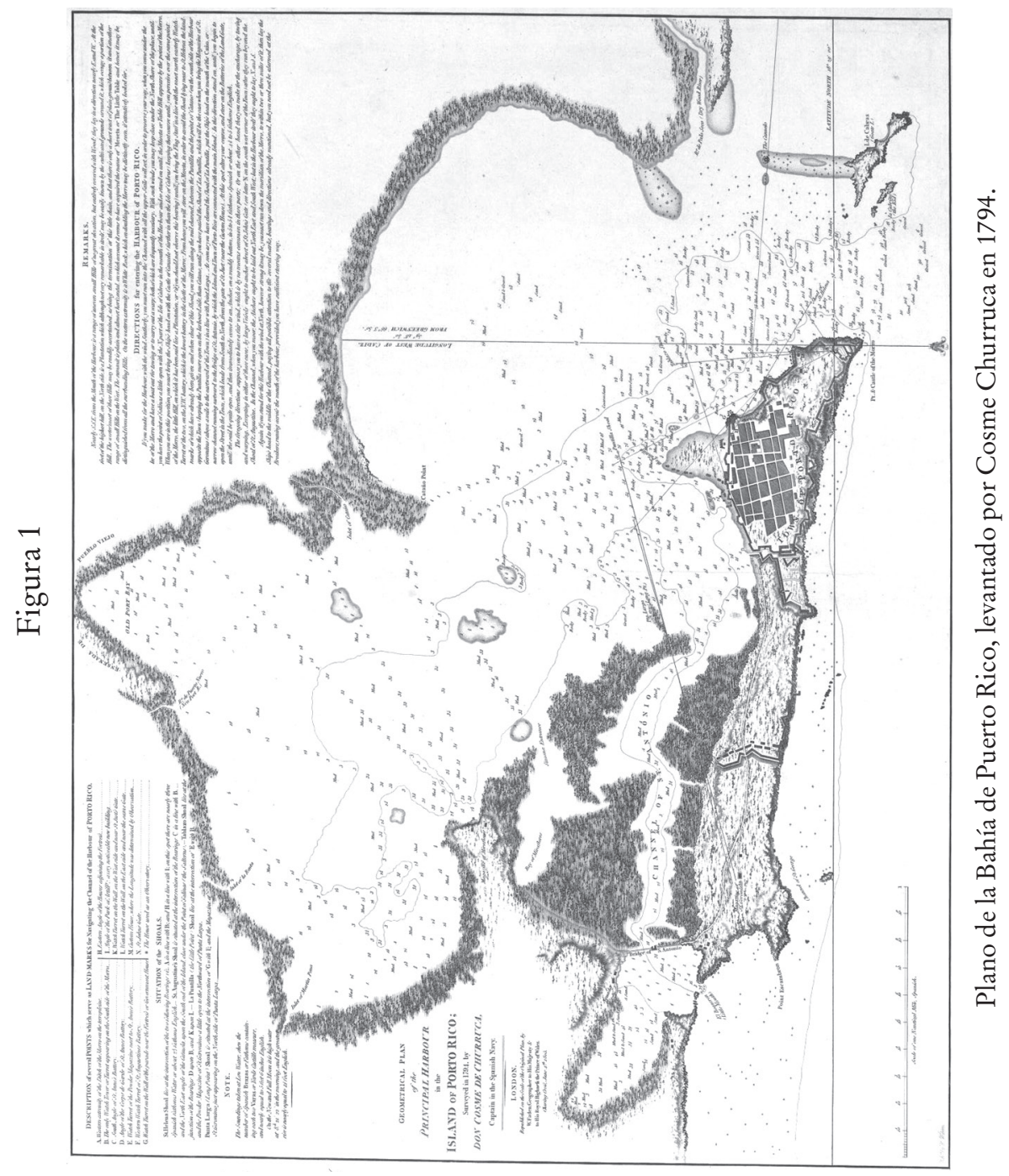


$2^{\circ}$ Una carta reducida del estrecho de Magallanes, construida por el Comandante y Oficiales de la fragata de S. M. Santa María de la Cabeza, y grabada por Vázquez en 1788.

$3^{\circ}$ Otra carta de varios planos grabada en 1786 por Pró: se contienen por lo correspondiente á la costa septentrional del estrecho de Magallanes el plano de la bahía de San Nicolás, el de otras tres bahías sin expresión de nombre, el de la bahía de Valcárcel, el del puerto de la Hambre, los del puerto de San Miguel y bahía de Gastón; y en la costa meridional los del puerto de San Antonio y bahía de Valdés.

$4^{\circ}$ Otra carta grabada también por Pró en dicho año de 86, que comprehende en la costa meridional del estrecho el plano del Laberinto de Córdoba; el de la bahía de Swallow o Baronesa; y en la parte de la costa septentrional el plano de puerto Galán y bahía del fuerte Escudo; el de la rada de Vacaro, el de la bahía de Aristizabal, y el de la bahía de Solano.

$5^{\circ}$ Otra carta reducida del propio estrecho de Magallanes desde el puerto de San Miguel hasta su desembocadura en el Océano Pacífico, construida sobre las observaciones hechas en los viajes de 1786 y 89 , y grabada por Cruz. ${ }^{25}$

Fueron sin duda unos resultados muy relevantes para la cartografía americana y el dominio de la marina española de este importante paso entre el Atlántico y el Pacífico. Casi un siglo después la Comisión Científica del Pacífico (1862-1866) no pudo mejorar las observaciones de estas campañas de la Marina ilustrada dirigidas por Antonio de Córdova. ${ }^{26}$

25 Salazar, Discurso sobre los progresos, p. 55.

26 Puig-Samper, Crónica de una expedición romántica. 
EXPEDICIÓN DEL ATLAS DE LA AMÉRICA SEPTENTRIONAL

Cosme de Churruca fue uno de los responsables - junto con Juan Francisco Fidalgo- de la conocida como expedición del Atlas de la América septentrional (1792-1805) que debía cartografiar parte del Caribe. ${ }^{27}$ Fue impulsada por José de Mazarredo con la construcción de cuatro bergantines y la dotación de un instrumental científico ya experimentado por la Marina española, como eran los cuartos de círculo de Ramsden, telescopios acromáticos, heliómetro, sextantes o quintantes, cronómetros, relojes de bolsillo de Arnold, teodolito, estuches de compases, etc., comprados en Londres, así como algunos fabricados en El Ferrol por José Baleato (transportadores de planos, anteojo, descriptor de elipses y otros instrumentos matemáticos), un total de 75 para cada una de las dos comisiones de la expedición. Las cartas náuticas, diarios y observaciones de la primera división al mando de Cosme de Churruca se almacenaron en la Dirección de Trabajos Hidrográficos hasta la llegada de los trabajos de la división de Juan Francisco Fidalgo, que permanecía en las Antillas, aunque José Espinosa y Tello dio a conocer algunos de ellos prematuramente, puesto que el trabajo de Fidalgo, se retrasaba y éste parecía estar cómodamente en el apostadero de Cartagena de Indias, hasta que en 1810 pasó a ocupar el cargo de director de la Academia de Guardia-Marinas y dos años después entregó finalmente sus trabajos cartográficos. Los resultados nos muestran sin duda el valor estratégico de estas campañas cartográficas e hidrográficas de la

27 González-Ripoll, A las órdenes de las estrellas; Lucena Giraldo, "El estudio de la travesía de Cartagena”. 


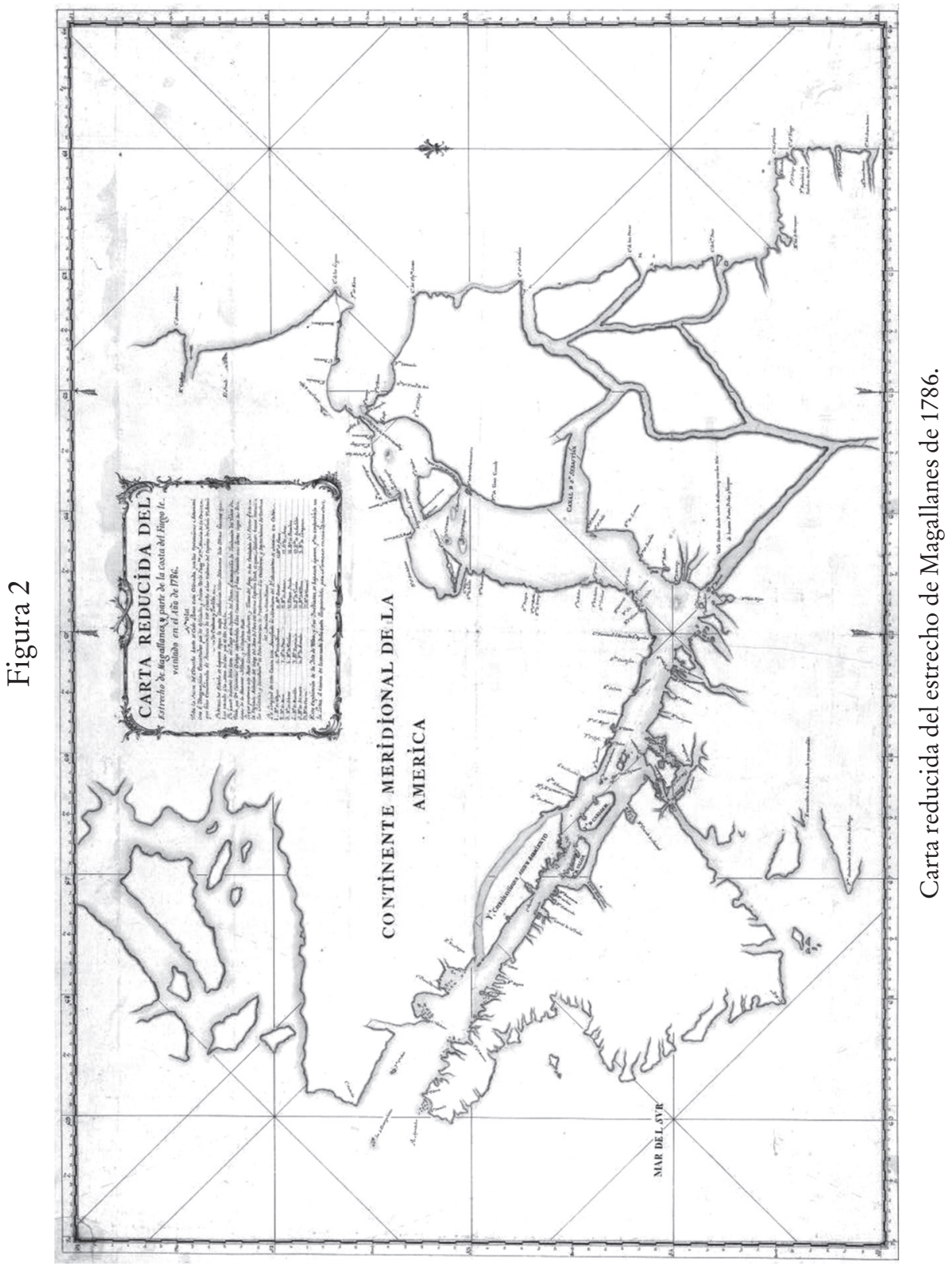


Marina española en este enclave estratégico para los intereses imperiales:

1.- Plano geométrico del puerto capital de la isla de Puerto Rico, Dirección de Hidrografía. 1794.

2.- Carta esférica de las islas Antillas con parte de la costa del continente de América, trabajada por los capitanes de navío D. Cosme Churruca y D. Joaquín Francisco Fidalgo, Dirección de Hidrografía, 1802.

3.- Carta esférica de las Islas Caribes de Sotavento, construida sobre operaciones geodésicas en 1793 por D. Cosme Churruca, brigadier de la Real Armada, Dirección de Hidrografía, 1804. 4.- Carta esférica de los canales que forman la isla de San Martín con las de San Bartolomé y Anguila, levantada geométricamente en 1794 por D. Cosme Churruca, Brigadier de la Real Armada, Dirección de Hidrografía, 1811.

5.-Plano del puerto Cabello en la Costa de Tierra Firme: situado el Castillo de San Felipe en latitud N.10'29'30" y longitud 6147’30", Dirección de Hidrografía, 1804.

6.- Carta esférica del Mar de las Antillas y de las costas de Tierra Firme desde las bocas del río Orinoco hasta el Golfo de Honduras, Madrid, Dirección de Hidrografía, 1810.

7.- Carta esférica de la isla Margarita y sus canales: con el Golfo del Cariaco en la costa firme / levantada en el año de 1793 por la $2^{\mathrm{a}}$ División de Bergantines del rey, Empresa y Alerta del mando del Brigadier de la Real Armada D. Joaquín Francisco Fidalgo, Madrid, Dirección de Hidrografía, 1816.

8.- Carta esférica de las costas de Tierra Firme: en quatro hojas; que comprende desde la longitud de $53^{\circ} 45^{\prime}$ occidental de Cádiz hasta $73^{\circ} 50^{\prime}$ del mismo meridiano / levantada de orden del rey desde 1793 hasta 1802 por la 2a División de Bergantines Empresa y Alerta al mando del Brigadier de la Rl. Armada Dn. 
Joaquín Francisco Fidalgo y publicada de orden de S. M. en la Dirección de Hidrografia, 1816.

9.- Carta esférica de parte de la costa del Darién del Norte: con las islas Mulatas que la hacen frente desde la de Pinos hasta la punta San Blas del Golfo del mismo nombre / levantada por orden del rey por la segunda División de Bergantines Empresa y Alerta al mando del Brigadier de la Real Armada D. Joaquín Francisco Fidalgo, Madrid, Dirección de Hidrografía, 1817.

\section{LA EXPEDICIÓN MALASPINA-BUSTAMANTE}

La política ilustrada diseñada por Carlos III, Carlos IV y sus ministros para conocer, reformar y asegurar las posesiones americanas del Imperio español con el envío de expediciones científicas, alcanzó su momento de mayor esplendor con la organización de la expedición alrededor del mundo de Alejandro Malaspina (1789-1794), navegante italiano al servicio de la Armada española. ${ }^{28}$

${ }^{28}$ Sobre la expedición de Alejandro Malaspina y José Bustamante existe una gran bibliografía, recogida en parte en el trabajo de SÁrz, Bibliografía sobre la expedición. Habría que mencionar, aunque sea levemente, además de la monumental edición de fuentes de Dolores Higueras en el Museo Naval y la edición del diario de Malaspina hecho por Palau et al., Viaje científico y político a la América meridional, también los trabajos de D. Cutter, Darío Manfredi, Virginia González Claverán, $M^{a}$ Luisa Martín Merás, R. Cerezo, E. Soler, Oldrich Kaspar, J. V. Polisensky, W. Cook, etc. El estudio de la vertiente política de la expedición fue realizado por Pimentel, La física de la Monarquía, quien ha publicado otros trabajos fundamentales para el estudio de la expedición, entre los que hay que destacar el estudio del ideario reformista en LuCENA Giraldo y Pimentel, Los "Axiomas políticos sobre la América". La perspectiva criolla se ve reflejada magistralmente en el reciente libro de SAGREDO BAEZA y GonzÁlez LeIva, La Expedición Malaspina en la frontera austral. 
El plan de la expedición, presentado por Malaspina en septiembre de 1788 al ministro Valdés, estaba orientado a la consecución de objetivos científicos, económicos y políticos dirigidos a fijar "los límites del imperio":

Excmo. Sr:: Desde veinte años a esta parte, las dos naciones, inglesa y francesa, con una noble emulación, han emprendido estos viajes, en los cuales la navegación, la geografía y la humanidad misma han hecho muy rápidos progresos: la historia de la sociedad se ha cimentado sobre investigaciones más generales; se ha enriquecido la Historia Natural con un número casi infinito de descubrimientos; finalmente, la conservación del hombre en diferentes climas en travesías dilatadas y entre unas tareas y riesgos casi increíbles, ha sido la requisión más interesante que ha hecho la navegación. Al cumplimiento de estos objetos se dirige particularmente el viaje que se propone; y esta parte, que puede llamarse la parte científica, se hará con mucho acierto, siguiendo las trazas de los Sres. Cook y La Pérouse.

Otros dos objetivos se esbozaban ligeramente: uno era la construcción de cartas hidrográficas para las regiones más remotas de la América, así como de derroteros que pudiesen guiar con acierto la poca experta navegación mercantil; y el otro la investigación del estado político de la América, así relativamente a España como a las naciones extranjeras. Se trataba, por tanto, de investigar de forma enciclopédica la naturaleza de los dominios imperiales, tanto desde el punto de vista histórico natural, con estudios dirigidos a todas las ramas del saber, como histórico político, para gobernar en estas posesiones con "equidad, utilidad y métodos sencillos y uniformes". El 14 de octubre de 1788, Malaspina recibió la notificación de Antonio Valdés en la que se aprobaba 
su proyecto de expedición, si bien se le advertía que la parte político económica del viaje se consideraría asunto reservado, en tanto que la científica quedaría como objetivo público de la expedición.

Una vez aprobada la gran empresa proyectada por Malaspina, comenzaron los preparativos con una minuciosidad y rapidez extraordinarias. Se dispusieron para el viaje dos corbetas de nueva construcción, la Descubierta y la Atrevida, capitaneadas por Alejandro Malaspina y José Bustamante y Guerra, respectivamente. Se realizaron consultas científicas a las Academias de Ciencias de Londres, París y Turín, al Observatorio de Cádiz y a sabios de la categoría de A. Ulloa, V. Tofiño, C. Gómez Ortega, J. Banks, F. Lalande y L. Spallanzani, que aportaron instrucciones para las diferentes ramas del saber.

Los libros y los instrumentos para el viaje de A. Malaspina fueron encargados a Londres y París, aunque el propio Observatorio de Cádiz pudo colaborar con algunos instrumentos y la fábrica de San Ildefonso con algunos frascos para experimentación física y química. ${ }^{29}$ José Mazarredo encargó a Jacinto Magallanes que comprara todo lo necesario en Londres, mediante los contactos ya establecidos. Como ejemplo podemos citar los anteojos ecuatoriales de Ramsdem, barómetros portátiles y todo tipo de utensilios, además de libros de geografía, astronomía, medicina, viajes, que incluían por supuesto los de Cook, y cartas. En París el Conde de Fernán Núñez se encargaba de los pedidos, por orden de Antonio Valdés, que le solicitaba una colección de libros e instrumentos dedicados al estudio

${ }^{29}$ González Claverán, “La Expedición Malaspina y su instrumental”. 
de la historia natural, además de aparatos como los higrómetros, termómetros para medir el agua del mar, aerómetros, balanza hidrostática portátil, escafandra, instrumentos meteorológicos, un presómetro de faltriquera, un eudiómetro, útiles de química, entre otros. ${ }^{30}$ Por otra parte, para

30 Sobre la práctica instrumental en la expedición véase Leyton y Saldivia, "La física en la Expedición Malaspina". Respecto a los instrumentos embarcados, según consta en EsPINOsa, Memorias sobre las observaciones astronómicas, 1809 , tomo I, memoria segunda, pp. xxxixxxii, eran los siguientes:

En la Descubierta

Un quarto de círculo astronómico de Ramsden.

Ocho sextantes y un círculo de reflexión.

Una equatorial de Dollond.

Dos acromáticos grandes.

Uno idem menor.

Un péndulo astronómico.

Un péndulo simple constante.

Dos Teodolites.

El relox de longitud de Berthoud núm. 13.

Los cronómetros de Arnold números 61 y 72, con su acompañante núm. 344.

Un relox de segundos para comparaciones.

Una aguja de inclinación de Nairne.

Dos agujas azimutales.

Dos barómetros marinos.

Varios termómetros.

Varios anteojos para objetos terrestres.

Un eudiómetro de Fontana.

Una balanza hidrostática.

Un microscopio.

Diferentes utensilios de geodesia é historia natural.

En la Atrevida

Un quarto de círculo astronómico de Sisson. 
obtener la documentación necesaria para realizar un viaje de tan vasto alcance, fue necesario que se autorizara el acceso a los principales archivos españoles con información sobre las Indias, así como a los americanos de temporalidades, gobierno, jesuitas expulsos, etcétera.

En cuanto al equipo científico de la expedición, hay que destacar que las tareas de carácter astronómico e hidrográfico recayeron en un grupo de oficiales de la Real Armada que en su mayoría ya tenían experiencia en estas tareas, por haber sido colaboradores del brigadier Vicente Tofiño en la elaboración del Atlas marítimo de España: Dionisio AlcaláGaliano, Cayetano Valdés, José Espinosa y Tello, Felipe Bauzá, etc... La selección del equipo de naturalistas fue algo más complicada, como ya había previsto Malaspina, por no haber en la Armada científicos preparados convenientemente en estas disciplinas. Finalmente se nombró encargado de los trabajos botánicos y de historia natural a Antonio de Pineda y Ramírez, militar que había completado sus estudios científicos en el Real Jardín Botánico y en el Real

Ocho sextantes de reflexión.

Un acromático grande.

Dos medianos.

Dos Teodolites.

El relox de longitud de Berthoud núm. 10.

El relox de faltriquera de Arnold núm. 105 propio del Comandante.

El cronometro de Arnold núm. 71, con su acompañante núm. 351.

Una aguja de inclinación de Nairne.

Dos agujas azimutales.

Dos barómetros marinos.

Varios termómetros.

Varios anteojos para objetos terrestres.

Un eudiómetro de Fontana.

Diferentes utensilios de geodesia é historia natural. 
Gabinete de Historia Natural de Madrid. Como botánico de la expedición se nombró a Luis Née, que en esos momentos desempeñaba su trabajo en el Jardín de la Priora, dependiente de la Botica Real, y como tercer miembro del grupo se designó al naturalista bohemio Tadeo Haenke, quien, incorporado en el último momento, tuvo que alcanzar a la expedición en Valparaíso.

La cartografía fue uno de los resultados más relevantes de la expedición Malaspina. Miles de millas cartografiadas de forma fiable fueron el regalo de la Marina española al resto del mundo, ya que los dibujos cartográficos fueron grabados en el Depósito Hidrográfico de Madrid y puestos a disposición de la comunidad internacional. Desde el inicio del viaje se corrigieron posiciones geográficas, como las del Teide y Trinidad del Sur, y comenzaron los trabajos cartográficos. Uno de los primeros resultados es la Carta esférica del Río de la Plata desde su desembocadura hasta Buenos Aires, dibujada por Felipe Bauzá y grabada en plancha por Fernando Selma en España. Contiene además los planos detallados de los puertos de Maldonado y Montevideo, con dos vistas de la costa de la embocadura del Río de la Plata y otra de la isla de Lobos. Del reconocimiento de la costa, con escalas en el Río Negro, Punta San José y detalles del Golfo de San Jorge, se levantará una Carta esférica de la América Meridional que incluye desde el Río de la Plata hasta el Cabo de Hornos, con las islas Malvinas y la costa del Pacífico hasta Chiloé, atendiendo a algunas exploraciones anteriores, como la de la Santa María de la Cabeza al estrecho de Magallanes, aunque con algunas rectificaciones de algunos puntos. De la isla de Chiloé se grabó por Antonio Vázquez el Plano del puerto de San Carlos, 
cuya plancha de cobre aún se conserva, y hay también cartas de algunos puertos patagónicos. En 1799 se publicó la carta que corresponde al territorio de Chile y comprende desde Concepción y Talcahuano hacia el norte, Santiago, Coquimbo, Copiapó y las islas de Juan Fernández y las de San Félix. Siguiendo la costa del Pacífico hacia el norte, Felipe Bauzá construyó una Carta esférica de la costa del Perú, fechada en 1798, que comprende la costa hasta Truxillo con seis vistas de costa y la derrota de las corbetas. Enlaza con esta la Carta esférica de la costa occidental de América, también realizada por Bauzá en 1800, que muestra el Ecuador y alcanza el istmo de Panamá. El detalle de los puertos del Callao y Concepción aparece en otra carta que se publicó en 1811, cuya plancha también se conserva. La continuidad geográfica se ve en la carta plana de la ría de Guayaquil que no se publicaría sino hasta 1825. Entre las producciones cartográficas hay una que desde luego hay que destacar por su belleza y precisión, la Carta esférica del interior de la América Meridional, con el itinerario de Valparaíso a Buenos Aires, fechada en 1810. Doce años después se publicaría la Carta esférica que comprende desde el Golfo Dulce en Costa Rica hasta San Blas en México, con varias vistas de costa. Desde esta localidad estratégica hasta Monterrey se elaboró una Carta esférica de la costa $y$ del golfo de California que fue publicada en 1825, siendo una de las más tardías. También se levantaron cartas de algunas zonas en la exploración hacia Alaska, como los planos de los puertos de Monterrey, Mulgrave y Desengaño o el de la Cala de los Amigos. Los expertos en cartografía han destacado también el trabajo realizado por las corbetas Descubierta y Atrevida en combinación con los de las 
goletas Sutil y Mexicana para elaborar las cartas hechas con los reconocimientos emprendidos en la costa noroeste de América, que incluyen también las cartas esféricas del estrecho de Juan de Fuca y las cartas de la isla de Bodega y Quadra, hoy conocida como Vancouver. Fuera de las costas americanas y fijándonos en el Pacífico, encontramos dos cartas generales de las islas Filipinas, una con la parte norte y el estrecho de San Bernardino destacado, y otra con la parte sur del archipiélago. Hay publicadas otras cartas concretas, como las de los puertos de Sorsogón y Palapa, o la Carta esférica de la Babía de Manila y los planos de Maribeles, Cavite y San Jacinto en la isla de Ticao, publicada en 1807, o la del estrecho de San Bernardino que tuvo que esperar hasta 1824. La última carta importante fue la Carta esférica del archipiélago de Babao, realizada en 1793, que además contiene el plano del fondeadero del Refugio y Puerto Valdés. En el mismo año los cartógrafos de la expedición levantaron un plano de Bahía Botánica y de Puerto Jackson en Australia, y un croquis del Puerto Dudoso - descubierto por el capitán Cook-, y del Puerto del Péndulo - llamado así por el capitán Malaspina-, hecho por Felipe Bauzá, que representa una zona de la isla sur de Nueva Zelanda conocida como Dusky Bay, en la que se ven los islotes de Née, la isla de Bauzá, el canal de la Descubierta, la punta de Quintano y el Canal de Malaspina. El croquis está depositado en la Bristish Hydrographic Office desde la época del exilio de Bauzá en Londres, en la que se relacionó estrechamente con los hidrógrafos británicos y con la Royal Society, de la que era miembro desde 1819. Además, la exploración del Pacífico sur de José Moraleda, que fue excepcional en las sucesivas comisiones que realizó entre 1772 y 1810 en 
expediciones al Callao y las costas del Perú, Chiloé, la costa patagónica occidental y América Central, aparece también conectada intelectualmente con Malaspina y el esfuerzo de la Marina española en la medición del territorio americano. ${ }^{31}$

Felipe Bauzá, el principal artífice de todo este gran trabajo cartográfico, se mostró siempre orgulloso de la producción de cartas por la expedición Malaspina y por su calidad, como podemos ver en el artículo que publicó en 1828 en la revista berlinesa Hertha titulado "Contribuciones a la hidrografía y geografía de América”. En las cartas con Martín Fernández de Navarrete y Alexander von Humboldt insistió en la excelencia de esta producción, que fue imprescindible desde entonces para la buena navegación y el conocimiento geográfico. ${ }^{32}$

Quizá el balance más general sobre la obra métrica de los marinos españoles se encuentre en la obra de Josef Espinosa Memorias sobre las observaciones astronómicas hechas por los navegantes españoles en distintos lugares del globo (Madrid, 2 vols., Imprenta Real, 1809), publicadas por la Dirección de Hidrografía con la intención de poner en valor las cartas recogidas por esta institución con las correspondientes memorias y mediciones realizadas en diferentes puntos del mundo. La obra presentaba cuatro memorias, la primera dedicada a lo correspondiente a las costas de España y África, el mar Mediterráneo, las islas Canarias y las Azores; la segunda dirigida a las costas del continente americano y sus islas, desde Montevideo al cabo

\footnotetext{
31 Sagredo Baeza, "Navegación científica” y "Navegando entre ríos de nieve".

32 Puig-Samper, Alejandro Malaspina.
} 
de Hornos, hasta los $60^{\circ}$ de latitud N.; la tercera dedicada a las islas Marianas, Filipinas, Nueva Holanda y el archipiélago de los Amigos, y la cuarta centrada en las costas de la América septentrional y sus islas, todas ellas con una gran información sobre la expedición de Alejandro Malaspina, en la que el propio Espinosa había participado y que había estado censurada por orden de Godoy. Según Luis María de Salazar, el intendente general de la Marina que introducía la obra de Espinosa, ya no sería legítimo que alguien preguntase ¿qué debe Europa a la nación española? La exploración y la medida de América y parte de la del globo terrestre daba la respuesta adecuada a esta pregunta.

Casi en paralelo aparecía en escena el sabio alemán Alexander von Humboldt como un científico atrapado entre la Ilustración y el Romanticismo, que amparado en su arsenal de instrumentos científicos para no perder la "objetividad", se permitía una observación nueva de la Naturaleza, más sensible y subjetiva, desde los presupuestos filosóficos del "empirismo razonado", como él mismo lo denominó, cercano ya al movimiento romántico.

\section{LA MEDIDA DEL MUNDO EN LA OBRA}

DE ALEXANDER VON HUMBOLDT

Humboldt, en la autobiografía entregada al barón de Forell, ${ }^{33}$ embajador de Sajonia en Madrid, para que se la hiciera llegar al ministro de Estado español Luis Mariano de Urquijo, indicaba que después de haber disfrutado de una educación muy cuidada en la casa paterna y de

33 Puig-Samper y Rebor, Sentir y medir. 
la enseñanza de los sabios más distinguidos de Berlín, acabó sus estudios en las universidades de Gotinga y Frankfurt. Destinado entonces a la carrera de hacienda, estuvo durante un año en la Academia de Comercio de Hamburgo, establecimiento dedicado tanto a la instrucción de negociantes, como a la de las personas que debían servir al Estado en la dirección del Comercio, de los bancos y de las manufacturas. El éxito que tuvo su primera obra sobre las montañas basálticas del Rhin, hizo que el Barón de Heinitz le contratara para su departamento en la dirección de Minas. Efectuó por entonces un viaje de mineralogía y de historia natural por Holanda, Inglaterra y Francia bajo la dirección de George Forster, célebre naturalista que había dado la vuelta al mundo con el capitán Cook. Según Humboldt, a él le debía la mayor parte de los conocimientos que poseía antes de su viaje americano. A la vuelta de Inglaterra aprendió la práctica de la minería en Freiberg y en Harz. Tras la incorporación a la corona de Prusia de Franconia, el rey lo nombró director de minas de estas provincias y estuvo dedicado a la práctica de la minería durante tres años. Fue durante esta estancia continuada en las minas cuando consiguió construir una nueva lámpara antimefítica, que no se apagaba con ningún gas, y una máquina de respiración, instrumentos que servían al mismo tiempo a los minadores militares.

Humboldt, en su autobiografía, describió sus últimas experiencias antes del viaje americano con las siguientes palabras:

Habiendo hecho por entonces algunos descubrimientos sorprendentes sobre el fluido nervioso y la manera de estimular los nervios por agentes químicos, aumentando y disminuyendo la 
irritabilidad a voluntad, sentí la necesidad de hacer un estudio más singular de Anatomía. Con este objeto estuve cuatro meses en la Universidad de Jena y publiqué los 2 volúmenes de mis Experiencias sobre los nervios y el proceso químico de la vitalidad, obra cuya traducción ha aparecido en Francia. Me trasladé de Jena a Dresde y Viena para estudiar las riquezas botánicas y para entrar nuevamente en Italia. Los sucesos de Roma me hicieron desistir de este proyecto y encontré durante mi estancia en Salzburgo un nuevo método para analizar el aire atmosférico, método sobre el cual he publicado una memoria con Vauquelin. Al mismo tiempo acabé la construcción de mi nuevo Barómetro y de un instrumento, que he llamado Antracómetro, porque mide la cantidad de ácido carbónico contenido en la atmósfera. Con la esperanza de poder llegar hasta Nápoles, partí hacia Francia, donde trabajé con los químicos de París durante 5 meses. Leí numerosas Memorias en el Institut National, contenidas en los Annales de Chimie, y publiqué dos obras, una sobre las mofetas de las minas y los medios de volverlas menos dañinas, la otra sobre el análisis del aire.

En cuanto a sus deseos de exploración, él mismo los describe con estas palabras:

Teniendo un ardiente deseo de ver otra parte del mundo y de verla con la referencia de la física general, de estudiar no solamente las especies y sus caracteres, estudio que se ha hecho casi exclusivamente hasta hoy día, sino la influencia de la Atmósfera y de su composición química sobre los cuerpos organizados; la formación del globo, las identidades de los estados en los países más alejados unos de otros, en fin las grandes armonías de la Naturaleza, tuve el deseo de dejar por algunos años el servicio del Rey y de sacrificar una parte de mi pequeña fortuna al progreso de las Ciencias. Solicité mi licencia, pero S. M. en 
lugar de concedérmela, me nombró su Consejero Superior de Minas, aumentando mi pensión y permitiéndome hacer un viaje de historia natural. No pudiendo ser útil a mi patria en una ausencia tan grande, no acepté la pensión, dando las gracias a S. M. por una gracia, menos acorde a mi poco mérito, que al de un padre, que gozó hasta su muerte de la confianza más distinguida de su Soberano.

Para preparar su viaje reunió una escogida colección de instrumentos científicos para poder determinar la posición astronómica de los lugares, la fuerza magnética, la declinación y la inclinación de la aguja imantada, la composición química del aire, su elasticidad, humedad y temperatura, su carga eléctrica, su transparencia, el color del cielo, la temperatura del mar, ${ }^{34}$ además de constituirse en una poderosa arma de autoridad ante la propia comunidad científica y sus públicos emergentes, fascinados por esta nueva ciencia instrumentalizada. ${ }^{35}$ Una ciencia que mediante estos nuevos instrumentos científicos, llamados también en Inglaterra filosóficos para distinguirlos de los antiguos instrumentos matemáticos, ${ }^{36}$ capaces de moverse espacialmente, podía aparentemente crear conocimientos objetivos y universales, aunque la realidad demostrara que dependían en gran medida de la habilidad del observador y de su capacidad para mantener y corregir los errores del propio instrumento, una

34 Sánchez Flores y Seeberger, “Humboldt y sus instrumentos científicos"; SeEberger, "Humboldt y sus instrumentos".

35 Valverde, Actos de precisión; Vega, Ciencia, arte e ilusión.

36 WARNER, "What is a scientific instrument". Un análisis detallado de la investigación métrica de Humboldt y el uso de sus instrumentos científicos en Ruiz Morales, La aventura métrica. 
especie de órgano muy sensible a los cambios producidos en sus desplazamientos por diferentes geografías. ${ }^{37}$

Años después recordaba cómo se había iniciado en el uso de los instrumentos científicos y especialmente en los astronómicos gracias al contacto con el astrónomo de origen húngaro Franz Xaver von Zach:

Tuve la ocasión, mucho tiempo antes de mi salida de Europa, de ocuparme del trazado de cartas y de medir alturas por medio del barómetro, pero hasta 1797 mis estudios no se habían dirigido hacia los conocimientos astronómicos. Animado desde entonces por los consejos del señor Zach, cuyo ejemplo y obras han contribuido tanto al progreso de la Astronomía y sus ciencias auxiliares en mi patria, me familiaricé con el uso de instrumentos y con la práctica de diversos métodos para fijar la posición de los lugares. Continué este ejercicio con observaciones y cálculos astronómicos durante mi residencia en Alemania, Francia y España. ${ }^{38}$

Siempre se ha dicho que Humboldt fue invitado por el capitán Baudin a unirse a su expedición en calidad de naturalista junto con Bonpland y otros científicos, lo que finalmente no sucedió por el retraso de la salida de este viaje austral y la marcha de Humboldt a España. Pero ahora lo que nos interesa es ver cómo, según una carta publicada recientemente por Michel Jangoux en una historia del viaje de Baudin, fechada el 21 de agosto de 1798, fue el propio Alexander von Humboldt quien se ofreció a participar

37 Cházaro, “Recorriendo el cuerpo"; Helden y Hankins, "Instruments"; Hankins y Silverman, Instruments and the Imagination.

${ }^{38}$ Нumboldt, Récueil d'observations astronomiques, pp. i-ii 
en este viaje. En dicha carta, enviada al naturalista Antoine Laurent de Jussieu, entonces director del Museo de Historia Natural, se presentaba como un joven entusiasta en el trabajo, reconocido por muchos sabios de París y sobre todo propietario de gran número de caros instrumentos científicos (40), construidos según él con la mayor exactitud y comparables con los mejores de Europa, que ofrecía en una tabla como demostración de su poderío, con el ofrecimiento de que todos los científicos de la expedición podrían usarlos, consciente de su capacidad para manejarlos y saber interpretar los datos y resultados ofrecidos por los mismos. ${ }^{39}$ Como curiosidad podemos indicar la adquisición anterior en Inglaterra de otro objeto singular, el conocido como baúl de Humboldt, encontrado en una hacienda colombiana y destinado al transporte de instrumentos científicos, ropas y mapas en el gran viaje americano. ${ }^{40}$

Poco después, tras el fracaso en el embarque con Baudin, y trasladados a España Humboldt y Bonpland, el primero presentaba una memoria al rey Carlos IV en 1799 en Aranjuez, en la que manifestaba sus intereses científicos. Resulta extremadamente interesante que Humboldt solicitara el permiso para penetrar en el Nuevo Mundo, alegando la perfección de los nuevos instrumentos de medición de los fenómenos atmosféricos, pero sobre todo haciendo hincapié en su particular obsesión, repetida en numerosas cartas a sus amigos, "la formación del Globo, la medida de las capas que lo componen y el reconocimiento de las relaciones generales que unen a los seres organizados"; objetivos

\footnotetext{
39 Jangoux, Le Voyage aux Terres Australes.

40 Paz Otero, "El baúl de Humboldt".
} 
que contrastan con lo señalado en el pasaporte y el permiso especial de Urquijo, que destacaban el estudio de las minas, una empresa más práctica para los gobernantes españoles:

Señor,

Imbuido de esta admiración respetuosa que inspira un Monarca, cuya augusta protección ha hecho florecer las ciencias y las artes, me atrevo a presentar a los pies de Su Majestad los deseos que me animan. Si es una audacia aproximarse a Su Trono, la esperanza que tengo de ser útil, quizá me da algún derecho a Su Clemencia. Dedicado desde hace varios años al estudio de la Naturaleza en Europa, deseo ardientemente trasladarme a esta parte del Globo, cuyas comarcas las más bellas y las más vastas gozan de las gracias de Su Majestad. Los progresos que han hecho desde hace algún tiempo las ciencias químicas y físicas, el uso de nuevos instrumentos, construidos para analizar la Atmósfera y conocer las propiedades a menudo tan nocivas para la vida del hombre; la reunión de todos estos medios augura una rica cosecha al Naturalista observador. No es, Señor, más que en la inmensa extensión de los Reinos sometidos a Vuestro Cetro, donde puede estudiarse la formación del Globo, medir las capas que lo componen, y reconocer las relaciones generales que unen a los seres organizados. Son estas consideraciones las que, con la aprobación del Rey, mi señor, me han conducido a la Península, son ellas, las que me hacen reclamar la augusta Protección de Su Majestad, para atreverme a penetrar en el nuevo mundo. No tengo otras razones para Su Clemencia que el celo que me anima, pero éste es apreciado por un Soberano, que no se cansa de hacer sacrificios para extender los conocimientos humanos. El éxito de mis investigaciones puede ser igual a las diligencias incansables, con las que me propongo hacerlas, para rendir el primer homenaje a Su Majestad y para probar a toda 
Europa, que no he sido enteramente indigno de la augusta Protección, con la que se ha dignado honrarme.

Es con la consoladora esperanza de ver cumplidos mis deseos, concebidos desde hace tanto tiempo, por lo que me atrevo a ponerme a los pies de Su Majestad, presentándole los homenajes de la veneración más profunda y de la obediencia más respetuosa, que conservaré, hasta el fin de mis días. ${ }^{41}$

En el pasaporte concedido al sabio prusiano para su recorrido americano, se ordenaba expresamente que no le impidieran

[...] por ningún motivo la conducción de sus Instrumentos de Física, Química, Astronomía y Matemáticas, ni el hacer en todas las referidas posesiones las observaciones y experimentos que juzgue útiles, como también el colectar libremente plantas, animales, semillas, y minerales, medir la altura de los montes, examinar la naturaleza de éstos, y hacer observaciones astronómicas.

Se manifestaba la admiración por esta nueva cultura científica que sacralizaba el instrumento científico como mediador que objetivaba el conocimiento sobre la realidad natural, tanto si se trataba de la observación del nuevo cielo, como del análisis de las sustancias desconocidas, la descripción de los objetos naturales destinados después a los gabinetes de historia natural o incluso para situar astronómicamente las ciudades más importantes del mundo. La satisfacción de Humboldt por el permiso concedido por la Corte española en una carta dirigida a su amigo Ludwig

${ }^{41}$ Puig-Samper, "Alejandro de Humboldt, un prusiano en la corte". Cursivas mías. 
Bollmann, en octubre de 1799, incidía de nuevo en sus queridos instrumentos, esos nuevos órganos capaces de observar mejor la naturaleza y extraer sus arcanos:

Decidido a pasar activamente mis años de juventud y con el afán de dejar a Europa por muchos años, me dirigí a Madrid con la gran colección de instrumentos que había adquirido. Allí conseguí, gracias al afecto personal del Rey y por medio del ministro de 27 años que entonces gobernaba en el país, un permiso sin parangón, por el que se me facultaba para llevar a cabo en las colonias españolas todos los experimentos físicos y de historia natural que puedan imaginarse.

Como ha indicado Santiago Galvis, ${ }^{42}$ Humboldt y Bonpland se convertían potencialmente "en productores de datos y exactitudes" en este periplo científico destinado al Nuevo Mundo, en un momento en el que los datos se habían convertido en la materia prima de las ciencias y los instrumentos científicos en los mediadores indispensables para conseguir logros científicos, según la opinión de MarieNoëlle Bourguet, quien además nos recuerda la inquietud de Humboldt al dirigirse a Banks en 1798 comunicándole que ya había reunido todos los instrumentos necesarios para un largo viaje, todavía de destino incierto. ${ }^{43}$ Como el propio Humboldt señala, a pesar de que los instrumentos habían sido hechos por los mejores constructores, quiso comprobar la fiabilidad de los mismos para disminuir en lo posible los errores en la medición, comparándolos con los instrumentos del Observatorio de París y calculando la longitud

42 Galvis, "Viajes, instrumentos y legitimación".

43 Bourguet, Licoppe y Sibum, Instruments, Travel and Science. 
de puntos ya conocidos y determinados por instrumentos muy exactos, operaciones en las que contó con la ayuda de Johan Tralles y del famoso Borda. Respecto a posibles imprecisiones debidas a la movilidad, las difíciles condiciones de las selvas, las montañas y en general el difícil territorio americano, Humboldt señalaba que no era necesaria una precisión de uno o dos segundos como sí lo era en la medida del arco de meridiano, declinaciones estelares, etc., ya que ahora se precisaban mediciones suficientes para mejorar la cartografía de estos territorios desconocidos e incluso mejorar las posiciones de algunos puntos y ciudades mal localizados, un problema que poco a poco se iba solucionando gracias a expediciones y viajes como los dirigidos por Cook, Lapérouse, Vancouver, Malaspina, Churruca, Galiano, Fidalgo, Cevallos, etc., en su afán por medir geográficamente el mundo conocido. ${ }^{44}$

Sobre los instrumentos fundamentales para la observación en la historia de la humanidad Humboldt llega a citar los siguientes:

El telescopio y la combinación que de él se ha hecho, muy tarde por desgracia, con los instrumentos de medida; el microscopio compuesto, que nos proporciona el medio de seguir los desarrollos de la materia orgánica, y de observar en los cuerpos aquella actividad eficaz que, según expresión de Aristóteles, es el principio de sus transformaciones; la brújula, y los diferentes mecanismos aplicados a la investigación del magnetismo terrestre; el péndulo empleado como medida del tiempo; el barómetro, el termómetro, los aparatos higrométricos y electrométricos; y por último, el polariscopio, destinado a la observación de

${ }^{44}$ Humboldt, Récueil d'observations astronomiques, pp. iv-v. 
los fenómenos de la polarización coloreada, ya sea que la luz irradie de los astros, ya que esté difundida por la atmósfera. ${ }^{45}$

Humboldt insistió siempre en que la contemplación del mundo se basaba en la observación reflexiva de los fenómenos naturales, en un encadenamiento de hechos considerables y en los inventos que habían ensanchado el círculo de la percepción sensible.

Los instrumentos que usaban entre los astrónomos de Alejandría para determinar los diversos puntos del espacio y medir los ángulos, eran reemplazados incesantemente por otros más perfectos, desde el antiguo gnomon y los escafos, hasta la invención de los astrolabios, de los armillos solsticiales y de los lineales dióptricos. Servido así el hombre en cierta manera por órganos nuevos, llegó gradualmente a una noción más exacta de todos los movimientos que se realizan en el sistema planetario. ${ }^{46}$

América había sido un territorio explorado durante dos siglos por los españoles y los criollos con una mirada a veces moderna pero fragmentaria y poco organizada en la reunión de resultados y su publicación, a pesar de disponer también, en algunos territorios como Nueva España, de un considerable arsenal de instrumentos científicos y de haber recibido multitud de expediciones científicas portadoras de esa modernidad europea que incluía la medición con instrumentos. Humboldt se disponía a llevar esa modernidad científica a América dotado de instrumentos que objetivaban la observación y aumentaban la precisión, sin perder

${ }^{45}$ Humboldt, Cosmos, p. 252.

${ }^{46}$ Humboldt, Cosmos, p. 291. 
la sensibilidad, y dispuesto a presentar una nueva síntesis holística del Nuevo Mundo a los europeos, que ya habían adquirido lo que Mary Louise Pratt ha llamado "conciencia planetaria". ${ }^{47}$

Alexander von Humboldt expresaba a su amigo David Friedländer desde Madrid, el 11 de abril de 1799, la verdadera naturaleza del objetivo científico de este viaje americano:

Pienso irme de aquí a mediados de mayo y embarcarme el 2 de junio en La Coruña rumbo a La Habana. Me acompaña mi gran colección de instrumentos químicos, físicos y astronómicos. Eche usted una mirada a la parte del mundo que pienso atravesar (medir y analizar) desde California a la Patagonia - ¡qué placer en esta naturaleza maravillosamente grande y novedosa! Nadie más se habrá dirigido a esta zona con un ánimo tan independiente, tan alegre, con un temperamento tan diligente. Voy a recoger plantas y animales, estudiar el calor, la elasticidad, el contenido magnético y eléctrico de la atmósfera, a analizarla, determinar longitudes y latitudes geográficas, medir montañas[...] Pero todo esto no constituye el objeto de mi viaje. Mi verdadero y único objetivo es investigar la confluencia e imbricación de todas las fuerzas naturales, la influencia de la naturaleza muerta en la creación de animales y plantas vivas. Con este fin he tenido que consultar todos los conocimientos empíricos. De ahí que aquellos que no saben lo que hago se quejen de que me ocupo de demasiadas cosas a la vez. Tenemos botánicos, minerálogos, pero ningún físico como lo exige la sylva sylvarum. ${ }^{48}$

Poco antes de partir del puerto de La Coruña escribía a su benefactor, el Barón de Forell, para agradecerle su

47 Pratt, Imperial Eyes.

48 Jahn y Lange, Die Jugengbriefe Alexander von Humboldts. 
protección y comunicarle su alegría por el apoyo de Rafael Clavijo, quien se había encargado de colocar sus instrumentos con mucho cuidado. Ya en las islas Canarias no dejaría de mencionar los mismos objetos, su obsesión, en una carta dirigida a Christian Friedrich Gödeking desde La Orotava, en la que le decía que todos sus instrumentos estuvieron en movimiento, analizando el aire, midiendo la altura del Teide, analizando la lava, etc., y que en el barco trabajaba como en un laboratorio, donde además le cuidaban con extrema precaución sus queridos instrumentos científicos, unos objetos que junto con los manuscritos y las colecciones no debían separarse del científico, y menos en una época de guerra. ${ }^{49}$

${ }^{49}$ Los instrumentos preparados por Alexander von Humboldt para su viaje americano fueron esencialmente: un sextante de Ramsden de 10 pulgadas de radio, con limbo de plata, graduación sexagesimal y divisiones cada 20 segundos; un horizonte artificial de Caroché, con nivel de burbuja y divisiones de dos segundos; un cuarto de círculo pequeño de Bird, con un radio de 12 pulgadas; un círculo repetidor de reflexión con 12 pulgadas de diámetro construido por Lenoir con dos espejos de platino, que finalmente no llevó; un teodolito de Hurter, de 8 pulgadas de diámetro, que tampoco fue embarcado por sus dificultades y poca precisión; un sextante de Troughton o de tabaquera; un anteojo centrado con un micrómetro grabado sobre vidrio; un anteojo acromático de 3 pies construido por Dollond; otro anteojo de menor longitud de Caroché; un reloj de longitud de Louis Berthoud; un semicronómetro de Seiffert; una brújula de inclinación de 12 pulgadas, construida por Lenoir con indicaciones de Borda; una gran aguja imantada, provista de pínulas y suspendida por el método de Coulomb; un magnetómetro de Saussure; una brújula de declinación de Lenoir; barómetros e higrómetros de Deluc y Saussure; un pluviómetro; termómetros; cianómetro; sondas termométricas; un aparato construido por Paul en Ginebra para medir con precisión la temperatura del agua hirviendo en las montañas; brújulas de bolsillo; cadenas de agrimensor; y prototipos métricos, en vidrio y metal, para verificar las medidas de longitud. Véase Нumboldt, Récueil d'observations astronomiques, pp. ii-iii. 
Desde Caracas escribía al astrónomo Lalande a finales de 1799 para manifestarle el importante trabajo experimental que llevaba realizado con sus instrumentos, que cargaban dos o tres mulas, así como la importante recolección naturalista con su compañero Bonpland, y cómo la emoción del lugar lo animaba a seguir con sus observaciones:

Dentro de un mes estaré en las cataratas de Río Negro, donde veré una naturaleza tan grande como salvaje, entre indios que se nutren de una mezcla de tierra arcillosa con grasa de cocodrilo. Voy con tres mulas que llevan los instrumentos. Será desde lo hondo de esta solitud donde formularé votos. La belleza de las noches del trópico me invitó a empezar un trabajo sobre la luz de las estrellas del Sur.

Al describir su mayor proeza atlética, la subida al volcán Chimborazo en Ecuador, acompañado de Bonpland y de Carlos Montúfar, Humboldt manifestaba al astrónomo Jean-Baptiste J. Delambre la magia de sentir la falta de oxígeno a gran altura, como una sensación física extraordinaria, en tanto que utilizaba sus instrumentos para verificar la altitud, la presión atmosférica, la temperatura, para objetivar el conocimiento de esta ascensión, así como de otras mediciones en el Cotopaxi, Tunguragua, Antisana, etc., y poder comunicarlo a los dignos próceres de la Académie des Sciences de París. ${ }^{50}$

La fe en sus instrumentos también llegaba a su fin cuando ya había superado el ecuador de su estancia americana y probablemente se encontraba cansado. Desde las primeras

50 Annales du Muséum National d'Historie Naturelle, An. XI, tomo II, 1803, pp. 170-180. 
páginas de su "Voyage au Nouveau Continent", Humboldt había expresado además las dificultades de transportar las colecciones de botánica, zoología y mineralogía y los instrumentos por la necesidad de llevarlos hasta en 20 mulas de carga, que se cambiaban cada 8 o 10 días, en una caravana de marcha lenta conducida por indios. ${ }^{51}$

Salimos mañana de aquí para Acapulco y no tengo otro deseo más que el de volver a la Europa. Los instrumentos finos no aguantan un viaje tan inmenso por caminos horrorosos y las ciencias físicas se mudan tan pronto en Europa que un viaje de esta Naturaleza no debe durar arriba de 3 a 4 años. ${ }^{52}$

Una afirmación que repetiría en una carta a Delambre desde México en 1803 al comunicarle que abandonaba el proyecto de visitar las islas Filipinas, además de por el peligro de perder sus manuscritos y dibujos, por el estado de sus instrumentos, ${ }^{53}$ aunque poco después volvía a acordarse de estos "objetos modernos" al pensar en una futura expedición a Asia, armado de sólidos conocimientos y de "instrumentos más exactos". ${ }^{54}$

Respecto a las semejanzas y diferencias en las medidas tomadas por las expediciones científicas españolas y las suyas propias, hay que decir que Humboldt las encontraba

${ }^{51}$ Humboldt y Bonpland, Voyage, pp. 6-9.

52 “Carta de Humboldt a José Pavón, Guayaquil, 13.2. 1803". ARANM, Madrid, ser. 16, leg. 42, doc. 2257.

53 Annales du Muséum National d'Historie Naturelle, An XII, t. III, 1804, p. 231.

${ }^{54}$ Annales du Muséum National d'Historie Naturelle, An XII, t. III, 1804, p. 404. 
Figura 3

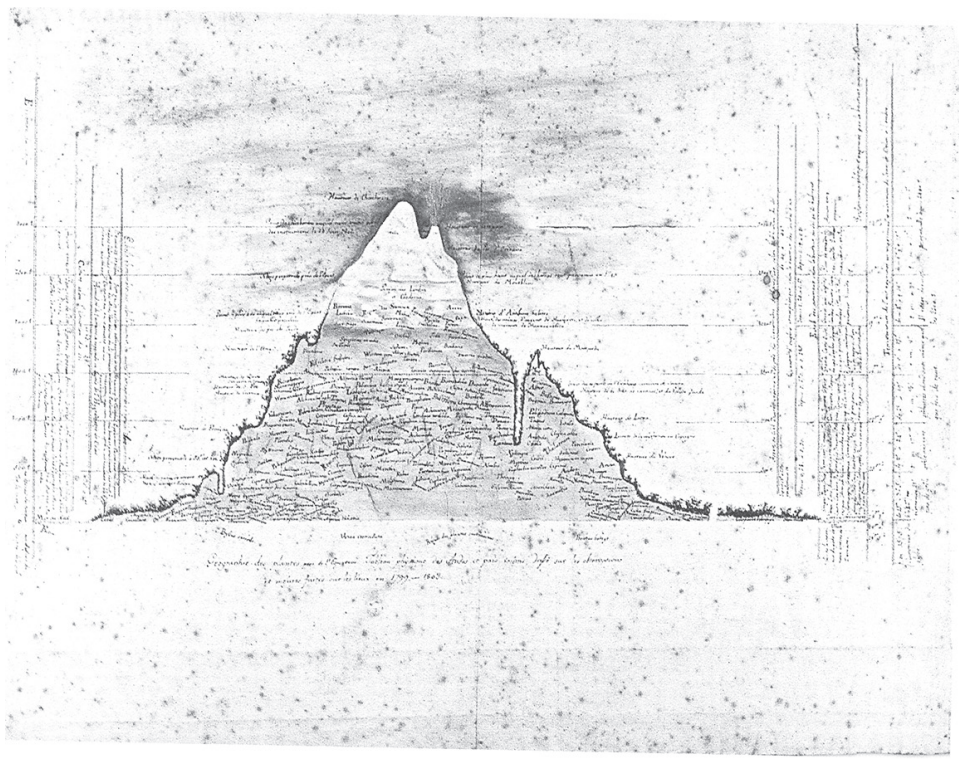

Bosquejo del dibujo de la Geografía de las plantas realizado por Humboldt en 1803. Museo Nacional de Colombia.

parecidas y alababa la labor de la Marina española en este periodo ilustrado:

Desde que se completó la impresión de este Compendio, he recibido por la amabilidad del Almirante Don Josef Mazarredo, que tanto contribuyó al progreso de la astronomía náutica, el análisis razonado de las cartas publicadas por el Depósito Hidrográfico de Madrid. Esta importante obra, escrita por el jefe de la Escuadra, Don Josef Espinosa, lleva el título de Memorias sobre las observaciones astronómicas hechas por los navegantes españoles en distintos lugares del globo (dos volúmenes en $4^{\circ}$, Madrid, 1809): ofrece observaciones originales hechas en 
las memorables expediciones de Malaspina, Churruca, Fidalgo, Galiano y Cevallos, que desde 1788 han cambiado, por así decirlo, la geografía de las costas de América. Como los navegantes españoles, equipados con instrumentos cada vez más numerosos y perfectos, han establecido la posición de un gran número de puntos que yo he determinado en mi viaje, tenemos la satisfacción, el Sr. Oltmanns y yo, de ver confirmados la mayor parte de los resultados en los que hemos trabajado. ${ }^{55}$

Hay que decir, sin embargo, que a pesar de estas continuas afirmaciones de Humboldt sobre el uso de sus instrumentos científicos para el estudio de la naturaleza, siempre insistió a sus más allegados que el fin último de su trabajo era el estudio de la física del mundo, la composición del globo, el análisis del aire, la fisiología de los animales y de las plantas, en fin, las relaciones globales que unían a los seres organizados con la naturaleza inanimada, siempre guiado por ese empirismo razonado que caracterizó a esta ciencia humboldtiana, determinada por la medición y la sensibilidad, en un momento clave del paso de la Ilustración al Romanticismo. ${ }^{56}$

\section{LA MEDIDA DEL CHIMBORAZO Y UNA NUEVA REPRESENTACIÓN}

Uno de los afanes en la obra de Humboldt fue medir y representar gráficamente, de manera sintética, aquellas observaciones científicas que con sumo esmero había realizado

55 Humboldt, Récueil d'observations astronomiques, pp. xxiii-xxiv.

56 Dettelbach, "Humboldtian science"; Dettelbach, "The face of nature”; Dettelbach, “Alexander von Humboldt”. 
con su imponente colección de instrumentos. Recordemos brevemente sus primeros perfiles topográficos en la península Ibérica, repetidos numerosas veces en territorio americano, su obra sobre la pasigrafía geológica, sus cortes geológicos, etc., debidos posiblemente a su interés por la síntesis y a su formación en la ingeniería de minas, donde había desarrollado estas habilidades técnicas. La parte métrica de la observación del Chimborazo la ofreció en su obra con Oltmanns, sin que aparentemente supusiera una gran novedad. Humboldt señala cómo hizo las mediciones en la llanura de Tapia en junio de 1803, cerca de Riobamba, entre la iglesia de la Merced y el convento de San Agustín, con simples cálculos trigonométricos, que dieron como resultado una altura de 3350 toesas para la cima del volcán por encima del nivel del mar, una medida que difería de la obtenida por La Condamine, de 3217 toesas y de la de Jorge Juan, de 3380 toesas, explicable según el sabio prusiano por errores en los cálculos de los ángulos y por la propia determinación de la altura de Quito. ${ }^{57}$ En cualquier caso, la metodología era parecida a la ya usada por otros viajeros y expedicionarios ilustrados. Lo realmente novedoso era el intento de crear un icón científico nuevo que sintetizara la información científica global y que además produjera un sentimiento estético en el observador.

Es evidente que el objetivo de esta representación iconográfica era crear un modelo ideal que transmitiera al público de manera sencilla el cúmulo inabarcable de multitud de observaciones, que por otra parte se consideraban objetivas en tanto que procedían de instrumentos más o menos

57 Нumboldt, Récueil d'observations astronomiques, pp. lxxii-lxxiv. 
fiables y se repetían un determinado número de veces para constatar la precisión de la medición. Por tanto, el propio Humboldt era consciente de que lo que ofrecía en imagen no era la realidad y en este caso ni siquiera una representación más o menos exacta, sino un modelo que resumía de forma visual su obra científica sobre América, de manera similar a los diagramas geobotánicos del abate Jean-Louis Giraud-Soulavie, quien ya en la década de 1880 había publicado unos cortes verticales con las medidas barométricas de las diferentes alturas de las montañas francesas relacionadas con las plantas naturales y cultivadas, o como intentaba representar en esos mismos años el neogranadino Francisco José de Caldas. ${ }^{58}$ De aquí procede su interés por publicar esta "Geografía de las Plantas" sin esperar a la edición del resto de su obra botánica con Bonpland, pues consideraba que daba las primicias científicas de su obra monumental. Humboldt, en su Cuadro físico de los Andes y países vecinos, construye un modelo científico que dibuja expresivamente la nueva geografía botánica, con intenciones estéticas añadidas, sin olvidar la frialdad de los datos científicos que ofrece en columnas laterales al Cuadro para no perder el interés central de la imagen del Chimborazo en todo su esplendor, precisamente el símbolo de la altura mitológica a la que había llegado el propio Alexander von Humboldt.

El Cuadro que ofrece Humboldt en 1805 es evidentemente una figura pintada por profesionales basada en sus notas. Realmente el dibujo espectacular que acompañó su obra publicada en París, ejecutado por Lorenz Schönberger

58 Bourguet, "Landscape with numbers"; Puig-SAmper, "La 'Geografía de las plantas' de Alexander von Humboldt”, pp. 435-446. 
y Pierre J. F. Turpin, en el que como él mismo apuntaba intentó combinar la exactitud con el efecto pintoresco, ${ }^{59}$ añadió otras escalas como las de refracciones horizontales, descenso de la luz, composición atmosférica, disminución de la gravedad, grado de agua hirviente a diferentes alturas, consideraciones geológicas, límites de la nieve perpetua o incluso la escala de las distancias desde las que eran visibles las montañas desde el mar. Apareció por fin como la imagen de la totalidad y la comparación en el estudio de la naturaleza, algo tan querido para su amigo Goethe, quien poco después le dedicaba un dibujo o esbozo de las principales alturas de los dos continentes, en el que se veía a Humboldt a los pies del Chimborazo en contraste con otros dos campeones de la ciencia y las alturas: Saussure en el Montblanc y Gay-Lussac volando a 3600 toesas de altura en su maravilloso globo aerostático.

Unos años más tarde y con el mismo espíritu, Humboldt representaría la "Geografía de las plantas" aplicada al Teide en un interesante dibujo publicado en el Atlas del viaje como Tableau physique des Iles Canaries. Géographie des Plantes du Pic de Tenerife, fundado además en las observaciones de sus amigos y colaboradores Leopold von Buch y Christian Smith. Fueron contribuciones decisivas para la geografía, especialmente para la nueva geografía de las plantas, y para el estudio comparado de las montañas en nuevas representaciones como las de su amigo Goethe o las de Tardieu.

59 Diener, "Lo pintoresco como categoría estética". 


\section{SIGLAS Y REFERENCIAS}

AGI Archivo General de Indias, Sevilla, España.

ARANM Archivo de la Real Academia Nacional de Medicina, Madrid, España.

MN Museo Naval, Madrid, España.

BATEs, David, “The epistemology of error in late Enlightenment France”, en Eighteenth-Century Studies, 29: 3 (1996), pp. 307-327.

BeErman, Eric, Francisco Requena. La expedición de limites: Amazonia, 1779-1795, Madrid, Compañía Literaria, 1996.

Bernabéu Albert, Salvador, "La Comisión española en la expedición de Chappe d'Auteroche”, en Peset (coord.), 1989, pp. 15-35.

Bernabéu Albert, Salvador, Las huellas de Venus. El viaje del astrónomo Chappe d'Auteroche a Nueva España (1768-1769), México, Breve Fondo Editorial, 1998.

Bernabéu Albert, Salvador, La aventura de lo imposible: expediciones marítimas españolas, Barcelona, Madrid, Lunwerg, 2000.

Bernabéu Albert, Salvador (ed.), Juan Francisco de la Bodega y Quadra, El descubrimiento del fin del mundo. 1775-1792, Madrid, Alianza, 1990.

Bernabéu Albert, Salvador (ed.), Trillar los mares. La expedición descubridora de Bruno de Hezeta al noroeste de América, 1775, Madrid, Fundación BBV, Consejo Superior de Investigaciones Científicas, 1995.

Bourguet, Marie-Nöelle, "Landscape with numbers. Natural history, travel and instruments in the late eighteenth and early nineteenth centuries”, en Bourguet, Licoppe y Sibum, 2003, pp. 96-125.

Bourguet, Marie-Nöelle, Christian Licoppe y Heinz Otto Sibum, Instruments, Travel and Science Itineraries of Precision from the Seventeenth to the Twentieth Century, Routledge Studies in the History of Science, Technology and Medicine, 16, Londres, Routledge, 2003. 
Cházaro García, Laura, "Recorriendo el cuerpo y el territorio nacional: instrumentos, medidas y política a fines del siglo xIx en México", en Memoria y Sociedad, 13 (27) (abr. 2014), pp. 101-119. http://revistas. javeriana.edu.co/index.php/memoysociedad/article/view/8231

Daston, Lorraine y Peter Galison, "The image of objectivity", en Representations, 40 (1992), pp. 81-128.

Dettelbach, Michael, "Humboldtian science”, en Jardine, Secord y SPARY (eds.), 1996, pp. 287-304.

Dettelbach, Michael, “The face of nature: precise measurement, mapping, and sensibility in the work of Alexander von Humboldt", en Studies in the History and Philosophy of the Biological and Biomedical Sciences, 30: 4 (1999), pp. 473-504.

Dettelbach, Michael, “Alexander von Humboldt between Enlightenment and Romanticism”, en Northeastern Naturalist, 8 (sp 1) (2001), pp. 9-20.

Diener, Pablo, "Lo pintoresco como categoría estética en el arte de viajeros: apuntes para la obra de Rugendas", en Historia, 40: 2 (2007), pp. 185-309.

EsPINOSA, Josef, Memorias sobre las observaciones astronómicas hechas por los navegantes españoles en distintos lugares del globo, Madrid, Imprenta Real, 1809, 2 volúmenes.

Fuster Ruiz, Francisco, El final del descubrimiento de América: California, Canadá y Alaska (1765-1822), Murcia, Universidad de Murcia, 1998.

GaLvis, Santiago, "Viajes, instrumentos y legitimación del quehacer científico de Alexander von Humboldt y su travesía por la Nueva España", en http://www.academia.edu/2181552/

González Claverán, Virginia, "La Expedición Malaspina y su instrumental científico”, en Quipu, 5: 1 (ene.-abr. 1988), pp. 143-160.

González-Ripoll, $\mathrm{M}^{\mathrm{a}}$ Dolores, $A$ las órdenes de las estrellas, Madrid, Fundación BBV-Consejo Superior de Investigaciones Científicas, 1995. 
Hankins, Thomas L. y Robert Silverman, Instruments and the Imagination, Princeton, Princeton University Press, 1995.

Helden, Albert Van y Thomas L. Hankins (eds.), "Instruments", en Osiris, 9 (1994), pp. 1-6.

Holl, Frank (ed.), Alejandro de Humboldt en México, México, Instituto Nacional de Antropología e Historia, 1997.

Holl, Frank (ed.), Alejandro de Humboldt. Una nueva visión del mundo, Barcelona, Lunwerg, 2005.

Humboldt, Alexander von, Récueil d'observations astronomiques, d'opérations trigonométriques, et des mesures barométriques, ... rédigées et calculées, d'après les Tables les plus exactes, par Jabbo Oltmanns, París, F. Schoell, 1810 [1811].

Humboldt, Alexander von, Cosmos. Ensayo de una descripción física del mundo, edición e introducción de Sandra Rebok, con presentación de Rafael Sagredo Baeza, prólogo de Miguel Ángel Puig-Samper y epílogo de Ottmar Ette, Madrid, Santiago de Chile, Los Libros de la Catarata, Consejo Superior de Investigaciones Científicas, Dirección de bibliotecas, Archivos y Museos, 2011.

Humboldt, Alexander von y Aimé Bonpland, Voyage aux régions équinoxiales du Nouveau Continent, París, Imp. de Smith, 1814-1825.

Jahn, Ilse y Fritz G. Lange, Die Jugengbriefe Alexander von Humboldts, 1787-1799, Berlín, Akademie-Verlag, 1973.

Jangoux, Michel, Le Voyage aux Terres Australes du Commandant Nicolas Baudin, París, PUPS, 2013.

Jardine, N., J. A. Secord y E. C. Spary (eds.), Cultures of Natural History, Cambridge, Cambridge University Press, 1996.

Lafuente, Antonio y A. J. Delgado, La geometrización de la Tierra (1735-1744), Madrid, Consejo Superior de Investigaciones Científicas, 1984. 
Lafuente, Antonio, "Retórica y experimentación en la polémica sobre la figura de la Tierra”, en Losada y VArela (eds.), 1995, pp. 125-140.

Lafuente, Antonio y Antonio Mazuecos, Los caballeros del punto fijo, Madrid, Barcelona, Serbal, Consejo Superior de Investigaciones Científicas, 1987.

Leyton A., Patricio y Zenobio Saldivia M., "La física en la Expedición Malaspina (1789-1794): ideología, práctica y experimentación”, en Intersticios Sociales, 10 (sep. 2015), pp. 1-32.

Losada, Manuel y Consuelo Varela (eds.), II Centenario de Don Antonio de Ulloa, Sevilla, Escuela de Estudios Hispanoamericanos, Consejo Superior de Investigaciones Científicas, Archivo General de Indias, 1995, pp. 125-140.

Lucena Giraldo, Manuel, Laboratorio tropical, Caracas, Monte Ávila, Consejo Superior de Investigaciones Científicas, 1991.

Lucena Giraldo, Manuel, "El estudio de la travesía de Cartagena de Indias a Cuba por la expedición hidrográfica del Atlas americano, 18031805”, en Asclepio, XLIII: 2 (1991), pp. 199-215.

Lucena Giraldo, Manuel y Juan Pimentel, Los "Axiomas políticos sobre la América” de Alejandro Malaspina, Aranjuez, Doce Calles, 1991.

Lucena Giraldo, Manuel y Antonio de Pedro, La frontera caríbica. Expedición de límites al Orinoco, Caracas, Lagoven, 1992.

Martín-Merás, Luisa, Cartografía marítima hispana. La imagen de América, Barcelona, Lunwerg, 1993.

Oliver, José Ma ${ }^{a}$, Clara Curell, Cristina G. Uriarte y Berta Pico (eds.), Escrituras y reescrituras de viaje, Nueva York, Oxford, Wien, Peter Lang, 2007.

Oyarzun, I., Exploraciones españolas al Estrecho de Magallanes y Tierra de Fuego, Madrid, Instituto de Cultura Hispánica, 1976. 
Padovani, Flavia, Alan Ricardson y Jonathan Tsou (eds.), Objectivity in Science. New Perspectives from Science and Technology Studies, Boston Studies in the Philosophy and History of Science, Springer, 2015.

Palau, Mercedes et al. (ed.), Viaje científico y político a la América meridional, a las costas del mar Pacífico y a las islas Marianas y Filipinas, verificado en los años de 1789, 90, 91, 92, 93 y 94, Madrid, El Museo Universal, 1984.

Paranhos de Rio-Branco, Miguel, Alexandre de Gusmão e o Tratado de 1750, Brasilia, Fundação Alexandre de Gusmão, 2010.

Paz Otero, Gerardo, "El baúl de Humboldt. Comunicado sobre un hallazgo histórico", http://publicaciones.banrepcultural.org/index.php/ boletin_cultural/article/view/3713/3839.

Peset, José Luis (coord.), Ciencia, vida y espacio en Iberoamérica, Madrid, Consejo Superior de Investigaciones Científicas, 1989, vol. III, pp. 15-35.

Pimentel, Juan, La física de la Monarquía. Ciencia y política en el pensamiento colonial de Alejandro Malaspina (1754-1810), Aranjuez, Doce Calles, 1998.

Pimentel, Juan, Testigos del mundo. Ciencia, literatura y viajes en la Ilustración, Madrid, Marcial Pons, 2003.

Pratt, Mary Louise, Imperial Eyes. Travel Writing and Transculturation, Londres, Routledge, 1992.

Puig-Samper, Miguel Ángel, Las expediciones científicas durante el siglo XVIII, Madrid, Akal, 1991.

Puig-Samper, Miguel Ángel, "Alejandro de Humboldt, un prusiano en la corte de Carlos IV”, en Revista de Indias, 216 (1999), pp. 329-355.

Puig-Samper, Miguel Ángel, "La 'Geografía de las plantas' de Alexander von Humboldt: la construcción del conocimiento científico y la prioridad del descubrimiento", en Oliver, Curell, Uriarte y Pico (eds.), 2007, pp. 435-446. 
Puig-Samper, Miguel Ángel, Crónica de una expedición romántica al Nuevo Mundo, Madrid, Polifemo, 2013.

Puig-Samper, Miguel Ángel, Alejandro Malaspina. Estudio crítico, Madrid, Fundación Ignacio Larramendi, 2016.

Puig-Samper, Miguel Ángel y Francisco Pelayo, El viaje del astrónomo y naturalista Louis Fenillée a las islas Canarias (1724), La Laguna, Centro de Cultura Popular Canaria, 1997.

Puig-Samper, Miguel Ángel y Sandra Reвoк, Sentir y medir. Alexander von Humboldt en España, Madrid, Doce Calles, 2007.

Ramos Pérez, Luis J., Las noticias secretas de América de Jorge Juan y Antonio de Ulloa (1735-1745), Madrid, Consejo Superior de Investigaciones Científicas, 1985, t. I, pp. 23-31.

Reis, Fernando, João Jacinto de Magalhães (1722-1790), en http://cvc. instituto-camoes.pt/ciencia/p4.html.

Relación del último viage al estrecho de Magallanes de la fragata de $S$. M. Santa María de la Cabeza en los años de 1785 y 1786, Madrid, Viuda de Ibarra, 1788.

Ruiz Morales, Mario, La aventura métrica de Alexander von Humboldt (1799-1804), Granada, Universidad de Granada, 2012.

SAfier, Neil, La medición del Nuevo Mundo. La ciencia de la Ilustración y América del Sur, Madrid, Marcial Pons, 2016.

SAfier, Neil, "Navegación científica en el Mar del Sur. El piloto Moraleda (1772-1810)", en Revista de Historia Iberoamericana, 2 (1), pp. 46-79.

SAgredo Baeza, Rafael, "Navegando entre ríos de nieve. El piloto Moraleda en la costa patagónica”, en Revista electrónica Documento/Monumento, 3 (1), pp. 51-72.

Sagredo Baeza, Rafael y José Ignacio GonzÁlez Leiva, La Expedición Malaspina en la frontera austral del imperio español, Santiago de Chile, Centro de Investigaciones Diego Barros Arana, Editorial Universitaria, 2004. 
SÁrz, Blanca, Bibliografía sobre la expedición Malaspina y su entorno, Madrid, El Museo Universal, 1992.

Salazar, Luis María, Discurso sobre los progresos y estado actual de la hidrografía en España, Madrid, Imprenta Real, 1789.

Sánchez Flores, Ramón y Max Seeberger, "Humboldt y sus instrumentos científicos”, en Holl (ed.), 1997, pp. 55-65.

Seeberger, Max, "Humboldt y sus instrumentos científicos”, en Holl (ed.), 2005, pp. 145-153.

Sellés, Manuel, Instrumentos de navegación. Del Mediterráneo al Pacífico, Barcelona, Lunwerg, 1994.

Valverde Pérez, Nuria, Actos de precisión. Instrumentos científicos, opinión pública y economía moral en la Ilustración española, Madrid, Consejo Superior de Investigaciones Científicas, 2007.

Vega, Jesusa, Ciencia, arte e ilusión en la España ilustrada, Madrid, Consejo Superior de Investigaciones Científicas, 2010.

WARNER, Deborah Jean, "What is a scientific instrument, when did it become one, and why?", en The British Journal for the History of Science, 23 (1990), pp. 83-93. 